Article

\title{
Docosane-Organosilica Microcapsules for Structural Composites with Thermal Energy Storage/Release Capability
}

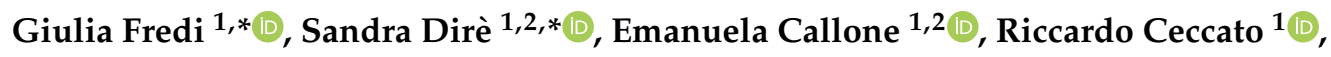 \\ Francesco Mondadori ${ }^{1}$ and Alessandro Pegoretti ${ }^{1, * \mathbb{D}}$ \\ 1 Department of Industrial Engineering and INSTM research unit, University of Trento, Via Sommarive 9, \\ 38123 Trento, Italy; emanuela.callone@unitn.it (E.C.); riccardo.ceccato@unitn.it (R.C.); \\ francesco.mondadori93@gmail.com (F.M.) \\ 2 "Klaus Müller" Magnetic Resonance Lab., Department of Industrial Engineering, University of Trento, \\ via Sommarive 9, 38123 Trento, Italy \\ * Correspondence: giulia.fredi@unitn.it (G.F.); sandra.dire@unitn.it (S.D.); alessandro.pegoretti@unitn.it (A.P.)
}

Received: 25 March 2019; Accepted: 17 April 2019; Published: 19 April 2019

\begin{abstract}
Organic phase change materials (PCMs) represent an effective solution to manage intermittent energy sources as the solar thermal energy. This work aims at encapsulating docosane in organosilica shells and at dispersing the produced capsules in epoxy/carbon laminates to manufacture multifunctional structural composites for thermal energy storage (TES). Microcapsules of different sizes were prepared by hydrolysis-condensation of methyltriethoxysilane (MTES) in an oil-in-water emulsion. X-ray diffraction (XRD) highlighted the difference in the crystalline structure of pristine and microencapsulated docosane, and ${ }^{13} \mathrm{C}$ solid-state nuclear magnetic resonance (NMR) evidenced the influence of microcapsules size on the shifts of the representative docosane signals, as a consequence of confinement effects, i.e., reduced chain mobility and interaction with the inner shell walls. A phase change enthalpy up to $143 \mathrm{~J} / \mathrm{g}$ was determined via differential scanning calorimetry (DSC) on microcapsules, and tests at low scanning speed emphasized the differences in the crystallization behavior and allowed the calculation of the phase change activation energy of docosane, which increased upon encapsulation. Then, the possibility of embedding the microcapsules in an epoxy resin and in an epoxy/carbon laminate to produce a structural TES composite was investigated. The presence of microcapsules agglomerates and the poor capsule-epoxy adhesion, both evidenced by scanning electron microscopy (SEM), led to a decrease in the mechanical properties, as confirmed by three-point bending tests. Dynamic mechanical analysis (DMA) highlighted that the storage modulus decreased by $15 \%$ after docosane melting and that the glass transition temperature of the epoxy resin was not influenced by the PCM. The heat storage/release properties of the obtained laminates were proved through DSC and thermal camera imaging tests.
\end{abstract}

Keywords: microencapsulated phase change materials; thermal energy storage; sol-gel organosilica; nuclear magnetic resonance; multifunctional composites; thermal properties

\section{Introduction}

Using phase change materials (PCMs) for thermal energy storage (TES) has become increasingly frequent in the last decades, as PCMs help to effectively manage intermittent energy sources, such as in the solar-thermal power plants or the solar-thermal systems for temperature regulation of buildings and water heating [1].

In these applications, PCMs have proven to be effective renewable energy materials, able to reduce the mismatch between energy availability and demand, thereby increasing the efficiency in energy 
utilization and reducing emissions [2-4]. Their superiority over the other TES systems, i.e., sensible heat and thermochemical heat materials, stems from their ability to store a high energy amount per unit mass in a narrow temperature interval. The most widely used PCMs, particularly in the low-medium temperature range $\left(0-120^{\circ} \mathrm{C}\right)$, are organic materials, such as paraffins, poly(ethylene glycol)s and fatty acids. Their main advantages are represented by the large availability, tunable working temperature, low density, cheapness, chemical inertness and non-corrosiveness [5-7]. However, two main drawbacks must be considered, namely the low thermal conductivity and the leakage above the melting temperature $[8,9]$. The latter issue can be addressed in several ways, such as the encapsulation and the shape stabilization with porous/layered materials or polymer matrices $[10,11]$. Among these, the most common is the encapsulation of the PCM in inert micro- or nano-shells, which not only avoid the loss of molten PCM due to leakage, but also enhance the heat transfer by increasing the specific surface area, protect the PCM from the external environment, increase the compatibility with the surrounding matrix, control the volume change during phase transition, and also improve the thermal conductivity and the thermal stability [12-14].

The capsule shell can be made of polymeric or inorganic material. Polymeric shells (acrylate polymers, polystyrene, melamine-formaldehyde resins, urea-formaldehyde resins, siloxane polymers [14-18]) are often the preferred choice, as they can be prepared with well consolidated and industrially available chemical techniques, such as coacervation or interfacial/emulsion/suspension polymerization $[13,19]$. The main advantage of polymeric shells is the low density, which allows a high core-to-shell weight ratio and therefore an enhanced total TES performance. On the other hand, organic shells are often highly flammable, can release toxic gases, and exhibit lower thermal and mechanical stability and lower thermal conductivity than their inorganic counterparts [20]. The most common inorganic shell material is silica [21], but many research studies have been carried out also on calcium carbonate [20], titanium dioxide [22,23], and aluminum hydroxide-oxide [24]. Microencapsulation technologies in inorganic materials mostly employ sol-gel techniques, starting from an oil-in-water $(\mathrm{O} / \mathrm{W})$ emulsion and alkoxysilane precursors [25-27]. For silica-based capsules, the most common precursor is tetraethyl orthosilicate (TEOS) $[21,28,29]$, but the resulting shell is often too brittle and is easily subjected to damages and cracks [30]. A valid alternative is methyltriethoxysilane (MTES), which leads to the formation of an organosilica network. Chen et al. [30] synthesized paraffin microcapsules with an organosilica shell starting from an $\mathrm{O} / \mathrm{W}$ emulsion (with commercial paraffin as the oil phase) and an MTES solution. The resulting capsules had an average diameter of $40-60 \mu \mathrm{m}$ and a phase change enthalpy of $50-80 \%$ of that of pure paraffin, according to the initial relative amount of paraffin and MTES. A similar procedure was adopted by Tang et al. [31], who encapsulated lower molecular weight paraffin (octadecane) and obtained microcapsules with a diameter of $0.5-2 \mu \mathrm{m}$. Lin et al. [12] encapsulated stearic acid in organosilica shells, and graphene oxide was added to enhance the thermal conductivity and improve the encapsulation efficiency.

Although these studies evidence the potentialities of sol-gel encapsulation and consider a quite broad range of PCMs, to the best of the author's knowledge, only one study has been reported on the production of organosilica microcapsules with docosane as the PCM [27], which specifically refers to the encapsulation of $\mathrm{n}$-docosane in $\mathrm{ZnO} / \mathrm{SiO}_{2}$ shells prepared from TEOS. Docosane features a high phase change enthalpy and a melting/crystallization temperature of $41 / 33^{\circ} \mathrm{C}$, which makes it suitable for a wide range of applications, including thermal regulating fabrics, passive cooling systems for electronic devices, solar space heating materials and other solar thermal energy applications [32-34]. Moreover, although the reported research investigates the microstructural properties of the microcapsules to some extent, no studies have been found that use powerful techniques, such as the nuclear magnetic resonance (NMR), to deeply examine the phase change behavior in a confined volume, and relate the results to the outcome of microstructural and thermal analyses, such as X-ray diffraction (XRD) and differential scanning calorimetry (DSC).

In most of the applications that need heat storage/management, the TES system is just an additional component that does not perform any other functions. However, this design approach 
increases weight and volume, which can be unacceptable for applications like automotive or portable electronics. This issue can be overcome by embedding the TES function directly in the structure of the device, with the help of multifunctional materials that can carry mechanical load and store/release thermal energy simultaneously. Such lightweight multifunctional materials could be polymer-matrix composites, as they combine the properties of different discontinuous phases embedded within a lightweight matrix [35]. Little has been done so far to develop and characterize such structural TES composites. Recently, our group prepared multifunctional epoxy/carbon laminates comprising carbon nanotubes-stabilized paraffin (CNTs) [36,37], polyamide/glass laminates with a microencapsulated and a shape-stabilized PCM [38,39], PCM-enhanced laminates starting from a novel reactive thermoplastic resin [40], and two types of semi-structural short carbon fibers composites including paraffin microcapsules, based on a thermoplastic (polyamide 12) [41] or a thermosetting (epoxy) [42] matrix, respectively.

Therefore, the aim of this research work is twofold. The first goal is to identify an effective sol-gel route to encapsulate docosane within organosilica shells of various dimensions and to deeply investigate how the confinement influences the microstructural and phase change properties of the PCM with a broad range of characterization techniques. The second purpose is to embed the prepared microcapsules in an epoxy/carbon laminate to produce a multifunctional structural TES composite, and to characterize the effect of the microcapsules on the mechanical properties of both the matrix and the laminate, and the overall TES capability of the system.

\section{Materials and Methods}

\subsection{Materials}

To prepare PCM microcapsules, n-docosane $\mathrm{CH}_{3}\left(\mathrm{CH}_{2}\right)_{20} \mathrm{CH}_{3}$, (purity $\geq 98.5 \%$ ), cetyltrimethylammonium bromide (CTAB) and absolute ethanol (purity $\geq 99.8 \%$ ) were purchased from Sigma-Aldrich (Saint Louis, MO, US), and methyltriethoxysilane (MTES) (purity $\geq 98 \%$ ) was provided by ABCR GmbH (Karlsruhe, Germany). Distilled water was used throughout all the process. All the materials were used as received, without further purification.

The prepared microcapsules were then embedded in multifunctional laminates, composed of a bi-component epoxy resin and a carbon fiber fabric. The epoxy resin Elan-tech ${ }^{\circledR}$ EC 157 and the hardener Elan-tech ${ }^{\circledR}$ W 342 were kindly provided by Elantas Europe S.r.l. (Collecchio (PR), Italy). Balanced plain weave carbon fiber (CF) fabric GG200P (mass per unit area $=192 \mathrm{~g} / \mathrm{m}^{2}, 3000$ fibers per tow, linear density 200 tex) was purchased from G.Angeloni S.r.l (Quarto d'Altino (VE), Italy).

\subsection{Preparation of the Microcapsules}

Docosane-organosilica microcapsules were prepared with a protocol based on that reported in [31], modifying some key synthesis parameters in order to improve the emulsion stability and to obtain capsules with remarkably different sizes. The docosane $\mathrm{o} / \mathrm{w}$ emulsion was prepared by adding $4 \mathrm{~g}$ of docosane and $0.05 \mathrm{~g}$ of CTAB to $50 \mathrm{~mL}$ water. The mixture was stirred for $30 \mathrm{~min}$ at $2500 \mathrm{rpm}$ via a Dispermat F1 laboratory dissolver (VMA-Getzmann GmbH, Reichshof, Germany), and then sonicated for $10 \mathrm{~min}$ with a UP400S ultrasonic processor (Hielscher GmbH, Teltow, Germany). During stirring and sonication, the temperature was kept at $60^{\circ} \mathrm{C}$, above the melting point of the docosane. After sonication, the $\mathrm{pH}$ was adjusted to $8-9$ by adding $\mathrm{NH}_{3(\mathrm{aq})} 1 \mathrm{M}$ solution. The MTES solution was prepared in a different beaker, by adding $4.2 \mathrm{~mL}$ of MTES to ethanol at $45^{\circ} \mathrm{C}$ under stirring. Then, $6.7 \mathrm{~mL}$ of $\mathrm{HCl}_{(\mathrm{aq})} 10^{-2} \mathrm{M}$ was added drop by drop to promote the acid-catalyzed hydrolysis of MTES, and the solution was magnetically stirred at $45^{\circ} \mathrm{C}$ for 20 minutes at $350 \mathrm{rpm}$. The MTES solution was then dropped into the docosane emulsion, and the total mixture was magnetically stirred at $60{ }^{\circ} \mathrm{C}$ at $350 \mathrm{rpm}$ for $4 \mathrm{~h}$. Finally, the suspension was filtered, and the filtrate was washed with hot water and ethanol (to remove free docosane and unreacted species) and dried overnight in a vacuum oven at $80^{\circ} \mathrm{C}$. The MTES solution was prepared with two different volumes of ethanol, 
i.e., $5.1 \mathrm{~mL}$ and $25.5 \mathrm{~mL}$ respectively, to modify the polarity of the synthesis medium and change the micelle size in the final suspension (MC1 and MC2). Each synthesis yielded approximately $2.5 \mathrm{~g}$ of microcapsules. Neat organosilica microparticles ( $\mathrm{Si}$ ) were also prepared without docosane and CTAB, under the same hydrolysis-condensation conditions [31,43]. The masses of the reagents for the three different preparations are reported in Table 1, while Figure 1 reports a schematic overview of the experimental protocol.

Table 1. Composition of the docosane o/w emulsion and the MTES solution for all the prepared samples.

\begin{tabular}{|c|c|c|c|c|c|c|}
\hline \multirow{2}{*}{ Sample } & \multicolumn{3}{|c|}{ Docosane o/w Emulsion } & \multicolumn{3}{|c|}{ MTES Solution } \\
\hline & Docosane (g) & СТАВ (g) & Water $(\mathrm{mL})$ & MTES (mL) & $\mathrm{HCl} 10^{-2} \mathrm{M}(\mathrm{mL})$ & ethanol (mL) \\
\hline MC1 & \multirow{2}{*}{5} & \multirow{2}{*}{0.05} & \multirow{3}{*}{50} & \multirow{3}{*}{4.2} & \multirow{3}{*}{6.7} & 5.1 \\
\hline MC2 & & & & & & 25.5 \\
\hline Si & - & - & & & & 5.1 \\
\hline
\end{tabular}

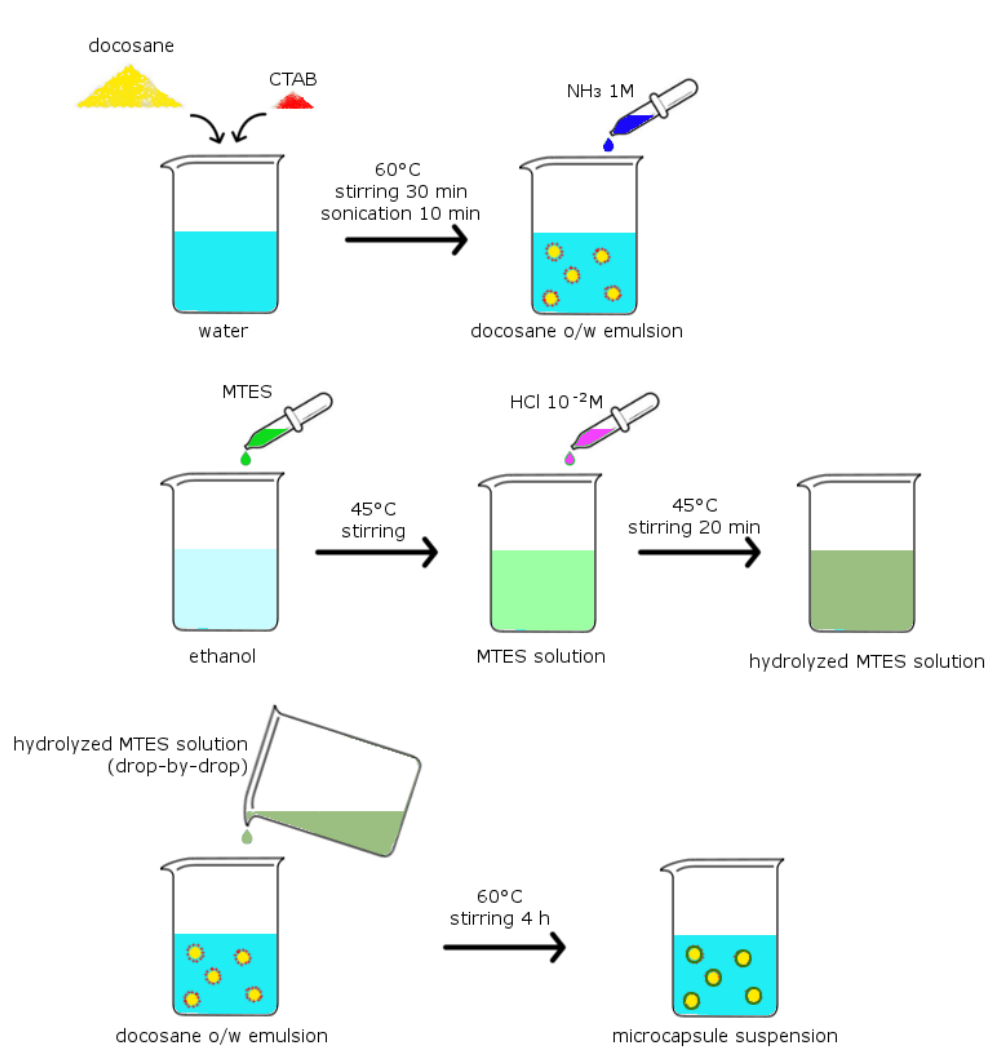

Figure 1. Experimental steps followed for the synthesis of the microcapsules.

\subsection{Preparation of the Epoxy-Based Matrices and Laminates}

The microcapsules denoted as MC2 were employed to prepare multifunctional laminates, with an epoxy matrix and a carbon fiber fabric. $2.5 \mathrm{~g}$ of dry microcapsules were dispersed in $17.5 \mathrm{~g}$ of epoxy base, and the mixture was mechanically stirred to obtain a homogeneous dispersion. After that, $5.2 \mathrm{~g}$ of hardener was added to the mixture, to reach the base:hardener ratio of 100:30, as indicated on the resin technical data sheet. The nominal capsule mass fraction was $10 \mathrm{wt} \%$. The mixture was then degassed and cast in silicon molds to prepare epoxy/MC samples for the subsequent characterization. The samples were cured for $24 \mathrm{~h}$ at room temperature and $10 \mathrm{~h}$ at $100{ }^{\circ} \mathrm{C}$. Specimens with neat epoxy were also prepared for comparison. The same epoxy/MC2 mixture was used as a matrix to prepare 5-ply laminates with a bi-directional CF fabric, with a traditional hand layup technique. The resulting laminates had in-plane dimensions of $100 \times 70 \mathrm{~mm}^{2}$. The laminates were vacuum bagged for $24 \mathrm{~h}$ 
at room temperature and post-cured at $100^{\circ} \mathrm{C}$ for $10 \mathrm{~h}$. Neat epoxy/CF laminates were prepared for comparison. The labeling adopted for the prepared epoxy-based samples is reported in Table 2.

Table 2. Labeling of the prepared epoxy-based matrices and laminates.

\begin{tabular}{ll}
\hline \multicolumn{1}{c}{ Sample } & Composition \\
\hline EP & Neat epoxy \\
EP-MC2 & Epoxy $+\mathrm{MC} 2(10 \mathrm{wt} \%)$ \\
EP-CF & Neat epoxy/carbon fiber laminate \\
EP-MC2-CF & Epoxy/carbon fiber laminate $+\mathrm{MC} 2(10 \mathrm{wt} \%$ with respect to the epoxy) \\
\hline
\end{tabular}

\subsection{Characterization of the Microcapsules}

The morphology of the microcapsules was investigated through a field-emission scanning electron microscope (FE-SEM) Zeiss Supra 60 (Zeiss, Oberkochen, Germany) operating in high vacuum mode, after Pt-Pd sputtering at $30 \mathrm{k}$ and $70 \mathrm{k}$ magnifications.

Fourier-transformed infrared spectroscopy (FTIR) was performed in attenuated total reflectance (ATR) mode with a Perkin Elmer Spectrum One instrument (Perkin Elmer, Waltham, MA, US). Data were collected in the wavenumber interval between 650 and $4000 \mathrm{~cm}^{-1}$, and four scans were superimposed for each spectrum (resolution $4 \mathrm{~cm}^{-1}$ ).

X-ray diffraction (XRD) measurements were collected by means of a Rigaku D-Max III powder diffractometer (Rigaku, Tokyo, Japan) using $\mathrm{Cu}-\mathrm{K} \alpha$ radiation $(\lambda=0.154056 \mathrm{~nm})$ and a graphite monochromator in the diffracted beam. A $\theta-2 \theta$ Bragg-Brentano configuration was adopted with the

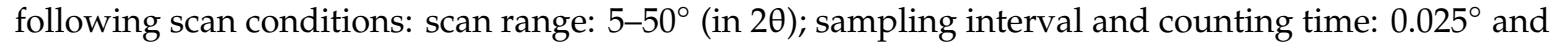
$2 \mathrm{~s}$, respectively.

Nuclear magnetic resonance (NMR) has been used to further investigate the structure and molecular dynamics of the microcapsules. Solid-state NMR analyses were carried out with a Bruker 400WB spectrometer (Bruker, Billerica, MA, US) operating at a proton frequency of $400.13 \mathrm{MHz} .{ }^{13} \mathrm{C}$ and ${ }^{29} \mathrm{Si}$ cross-polarization (CP) magic angle spinning (MAS) spectra and proton-decoupled MAS spectra were collected. Spectra with CP pulse sequences were acquired under the following conditions: ${ }^{13} \mathrm{C}$ frequency: $100.48 \mathrm{MHz}, \pi / 2$ pulse: $3.5 \mu$ s, decoupling length: $5.9 \mu$ s, recycle delay: $4 \mathrm{~s}, 512$ scans; contact time: $2 \mathrm{~ms} .{ }^{29} \mathrm{Si}$ frequency: $79.48 \mathrm{MHz}$, contact time: $5 \mathrm{~ms}$, decoupling length: $6.3 \mu \mathrm{s}$, recycle delay: 20 s, 2k scans. Quantitative and relaxation experiments are detailed in the Supplementary Materials. Samples were packed in $4 \mathrm{~mm}$ zirconia rotor and spun at $8 \mathrm{kHz}$ under air flow. Adamantane and $\mathrm{Q}_{8} \mathrm{M}_{8}$ were used as external secondary references. Si units were labeled according to the usual NMR notation, $\mathrm{T}^{\mathrm{n}}$ representing trifunctional $\mathrm{Si}$ units with $\mathrm{n}$ bridging $\mathrm{O}$ atoms.

Differential scanning calorimetry (DSC) was performed to study the variation in the phase transition temperature and enthalpy values of docosane in its bulk and encapsulated state. Specimens of approx. $8 \mathrm{mg}$ were sealed in aluminum crucibles and tested in a Mettler DSC 30 calorimeter (Mettler Toledo, Columbus, $\mathrm{OH}$, USA), at $10{ }^{\circ} \mathrm{C} / \mathrm{min}$, between 0 and $70{ }^{\circ} \mathrm{C}$, under a nitrogen flow of $100 \mathrm{~mL} / \mathrm{min}$. The employed cooling medium was liquid nitrogen. A heating scan, a cooling scan, and a second heating scan were performed for each specimen. The test allowed the measurement of the melting and crystallization temperatures $\left(T_{m}, T_{c}\right)$ and enthalpy values $\left(\Delta H_{m}, \Delta H_{c}\right)$ of the PCM phase. The encapsulation efficiency $\eta$ was evaluated for each sample as the ratio between its phase change enthalpy and that of the neat docosane, through Equation (1), as

$$
\eta=\frac{\Delta H_{m}^{M C}+\Delta H_{c}^{M C}}{\Delta H_{m}^{D}+\Delta H_{c}^{D}}
$$

where $\Delta H_{m}^{M C}$ and $\Delta H_{c}^{M C}$ are the melting and crystallization enthalpy values of the microcapsules and $\Delta H_{m}^{D}$ and $\Delta H_{c}^{D}$ are those of the neat docosane. 
Moreover, a kinetic analysis was performed on neat docosane and MC1 to investigate the effect of encapsulation on the activation energy of the phase change. Tests were performed a $10{ }^{\circ} \mathrm{C} / \mathrm{min}$, $1{ }^{\circ} \mathrm{C} / \mathrm{min}$ and $0.2^{\circ} \mathrm{C} / \mathrm{min}$. The activation energy $E_{a}$ was determined as the slope of the linear regression, through a standard Arrhenius approach, as reported in Equation (2):

$$
\frac{d \ln (\vartheta)}{d\left(\frac{1}{T_{p}}\right)}=-\frac{E_{a}}{R},
$$

where $\vartheta$ is the heating or cooling rate, $T_{p}$ is the peak phase change temperature (in $\mathrm{K}$ ) and $R$ is the universal gas constant, equal to $8.314 \mathrm{~J} / \mathrm{mol} \cdot \mathrm{K}$.

Lastly, thermogravimetric analysis (TGA) was performed to study the thermal stability of the docosane and the microcapsules. The tests were performed on a Mettler TG50 instrument (Mettler Toledo, Columbus, OH, USA). Specimens of approx. $15 \mathrm{mg}$ were tested at $10^{\circ} \mathrm{C} / \mathrm{min}$ up to $700^{\circ} \mathrm{C}$, under a nitrogen flow of $100 \mathrm{~mL} / \mathrm{min}$. The test allowed the measurement of the temperatures corresponding to a mass loss of $1 \mathrm{wt} \%\left(T_{1 \%}\right), 3 \mathrm{wt} \%\left(T_{3 \%}\right)$, and $5 \mathrm{wt} \%\left(T_{5 \%}\right)$, as well as the peak temperatures of the mass loss derivative signal, corresponding to the maximum degradation rate of the docosane $\left(T_{p}^{D}\right)$ and organosilica $\left(T_{p}^{S i}\right)$ phases. Moreover, the weight fraction of docosane $\left(\omega_{D}^{T G A}\right)$ could be estimated for each sample from the mass loss after the degradation of this phase, and the residual mass after the test $\left(R_{700^{\circ} \mathrm{C}}\right)$ was also measured.

\subsection{Characterization of the Epoxy-Based Matrices and Laminates}

For the microstructural analysis, specimens of matrices and laminates were cryogenically fractured in liquid nitrogen, and the fracture surface was observed with the FE-SEM Zeiss Supra 60 scanning electron microscope (Zeiss, Oberkochen, Germany), in high vacuum mode, after Pt-Pd sputtering.

DSC and TGA analyses were performed with the same procedure described in the previous paragraph for the characterization of the microcapsules. From the DSC tests, an experimental content of docosane in each sample was calculated with Equation (3), as

$$
\omega_{D}^{D S C}(w t \%)=\frac{\Delta H_{m}}{\Delta H_{m}^{D}}
$$

where $\Delta H_{m}$ is the experimental melting enthalpy measured on each epoxy-based sample. Moreover, the microcapsule weight fraction was experimentally determined according to Equation (4), as

$$
\omega_{M C 2}^{D S C}(w t \%)=\frac{\Delta H_{m}}{\Delta H_{m}^{M C 2}}
$$

where $\Delta H_{m}^{M C 2}$ is the experimental melting enthalpy of the microcapsules MC2. These results were then compared with those obtained in TGA tests.

The TGA analyses lead to the measurement of the degradation temperatures $T_{1 \%}, T_{3 \%}$ and $T_{5 \%}$, as reported for the characterization of the microcapsules, as well as the peak temperatures of the mass loss derivative signal, corresponding to the maximum degradation rate of the docosane $\left(T_{p}^{D}\right)$ and epoxy $\left(T_{p}^{E P}\right)$ phases. Moreover, the fiber weight fraction could be calculated from the residual masses at the end of the test, also by considering the residual masses of EP and EP-MC2 matrices. From these results, a theoretical density was calculated and compared with the experimental density obtained via the Archimedes' balance technique weighing the samples in ethanol $\left(\rho_{E t O H}=0.80458 \mathrm{~g} / \mathrm{cm}^{3}\right.$, measured at $20^{\circ} \mathrm{C}$ ) with a Gibertini E42 analytical balance (Gibertini, Novate Milanese (MI), Italy). This comparison allowed the calculation of the volume fraction of pores. Additionally, from the TGA tests, the degraded mass at $260{ }^{\circ} \mathrm{C}$ (i.e., immediately after the degradation of the docosane phase) was employed to determine an experimental weight fraction of docosane, which was compared with that obtained with DSC measurements. 
Three-point flexural tests were performed according to ASTM D790-03 standard with an electromechanical dynamometer Instron 5969 (Instron, Norwood, MA, USA), equipped with a $50 \mathrm{kN}$ load cell. Three specimens were tested for each sample. For samples EP and EP-MC, the test was performed at a crosshead speed of $1.5 \mathrm{~mm} / \mathrm{min}$, on casted specimens with nominal dimensions of $70 \times 10 \times 3 \mathrm{~mm}^{3}$, which were tested flatwise with a span length of $50 \mathrm{~mm}$. The tangent modulus of elasticity $(E)$, the flexural strength $\left(\sigma_{f M}\right)$ and the flexural strain at break $\left(\varepsilon_{b}\right)$ were determined with Equations (5)-(7), as

$$
\begin{gathered}
E=L^{3} m / 4 b d^{3}, \\
\sigma_{f M}=3 P L / 2 b d^{2}, \\
\varepsilon_{b}=6 D d / L^{2},
\end{gathered}
$$

where $L$ is the support span, $m$ is the slope of the tangent to the initial portion of the load-deflection curve, $b$ and $d$ are the specimen width and thickness, $P$ is the maximum load and $D$ is the deflection at the break point. For the samples EP-CF and EP-MC-CF, specimens with nominal dimensions of $70 \times 10 \times 3 \mathrm{~mm}^{3}$ were cut from the prepared laminates by a diamond wheel and tested flatwise with a span length of $70 \mathrm{~mm}$ and at a crosshead speed of $9 \mathrm{~mm} / \mathrm{min}$. The values of $E$ and $\varepsilon_{b}$ were determined with Equations (5) and (7), respectively, but the value of $\sigma_{f M}$ was determined with the Equation (8), as

$$
\sigma_{f M}=\frac{3 P L}{2 b d^{2}}\left[1+6\left(\frac{D}{L}\right)^{2}-4\left(\frac{D}{L}\right)\left(\frac{d}{L}\right)\right]
$$

to consider the not negligible forces developed at the supports that come from the considerably high span-to-thickness ratio, necessary when the in-plane resistance is remarkably higher than the interlaminar resistance, as it is often true in case of laminates.

A quick test was performed to check the overall thermal management performance of the laminates. Each laminate was heated in an oven for $30 \mathrm{~min}$ at $60^{\circ} \mathrm{C}$, above the melting temperature of docosane, then taken out and left cooling down to room temperature under laboratory conditions. During the cooling phase, the surface temperature was recorded with an infrared thermal imaging camera FLIR E60 (FLIR, Limbiate (MB), Italy), placed at approx. $30 \mathrm{~cm}$ from the sample.

Dynamic mechanical thermal analysis (DMA) was performed on the laminates to investigate the effect of the phase transition of docosane on the viscoelastic properties. The tests were performed with a TA Q800DMA instrument (TA Instruments, New Castle, DE, USA), on specimens with nominal in-plane dimensions $35 \times 5 \mathrm{~mm}^{2}$ and the thickness of each laminate. The tests were performed in single cantilever mode, and the distance between the grips was fixed at $17.5 \mathrm{~mm}$. Storage modulus and loss modulus were measured in the range $-20-140{ }^{\circ} \mathrm{C}$ at $3{ }^{\circ} \mathrm{C} / \mathrm{min}$, with an applied strain of $0.05 \%$ at a frequency of $1 \mathrm{~Hz}$.

\section{Results and Discussion}

\subsection{Characterization of the PCM Microcapsules}

\subsubsection{Sample Preparation and Quality of the Docosane o/w Emulsion}

The first part of the activity was focused on optimizing the emulsion parameters to maximize the encapsulated docosane. Since an important factor is the choice of the surfactant, a first attempt was made with sodium dodecyl sulfate (SDS), employed in many research works to obtain o/w emulsions with different types of paraffins $[12,13,21-23,28,30,31]$. However, it was noticed that with docosane this surfactant is not highly effective and leads to low fractions of emulsified paraffin. This behavior could be related to the higher molecular weight of docosane with respect to the paraffins employed in other studies (e.g., octadecane, eicosane). Nevertheless, most of the considered works do not report information on the quality of the emulsion nor on the synthesis yield, related to the ratio of encapsulated paraffin with respect to the initial amount, and therefore it is difficult to make a direct 
comparison. It should be pointed out that the study of PCM emulsion stability is important not only to maximize the final encapsulation yield but also for the development of high performing heat transfer fluids [44-46], which often contain emulsified PCM. In the present study, considerably more effective emulsification of docosane was obtained with CTAB, probably due to its higher hydrophobic character denoted by its lower hydrophile-lipophile balance (HLB) number [26,47-49].

\subsubsection{SEM Micrography}

Figure 2a-f reports SEM micrographs of the prepared microcapsules.

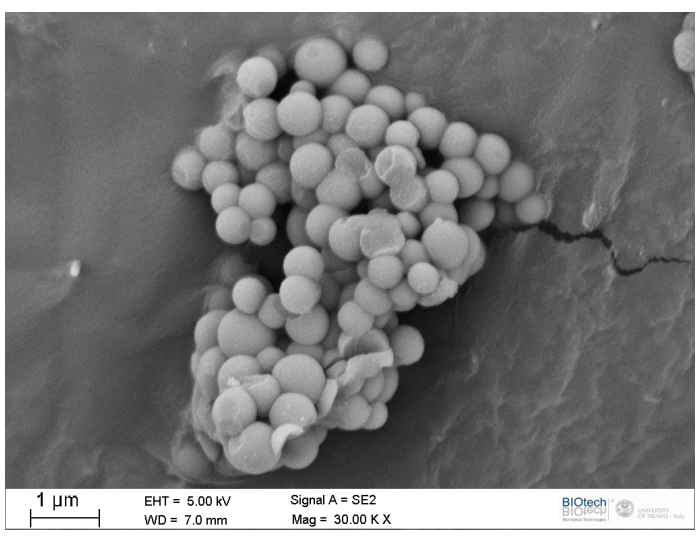

(a)

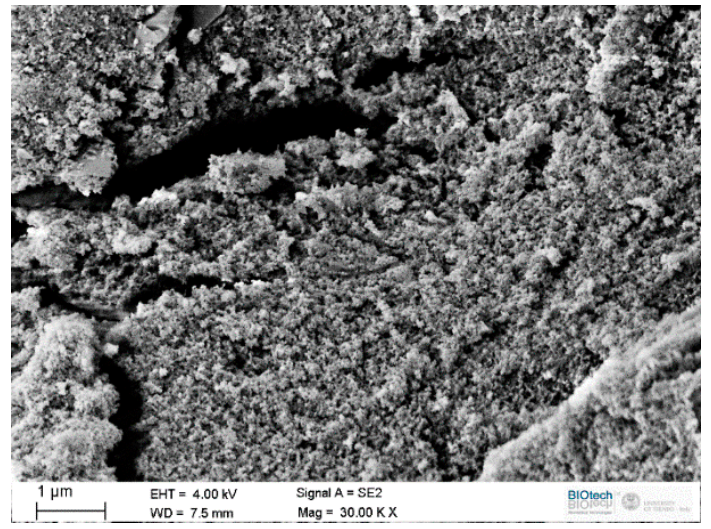

(c)

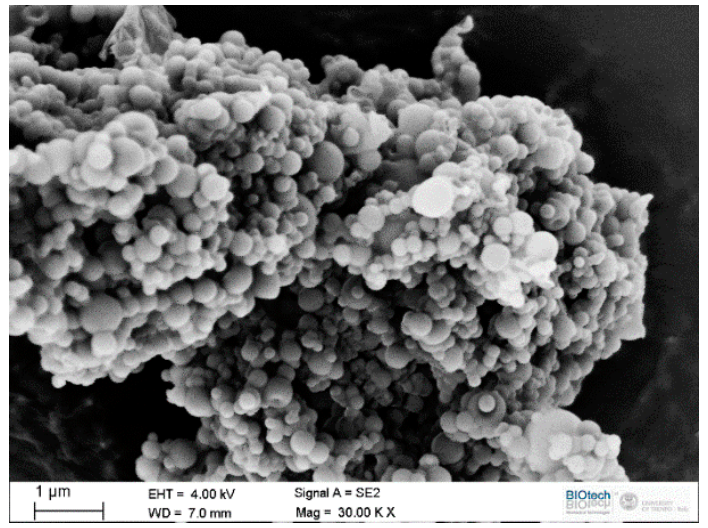

(e)

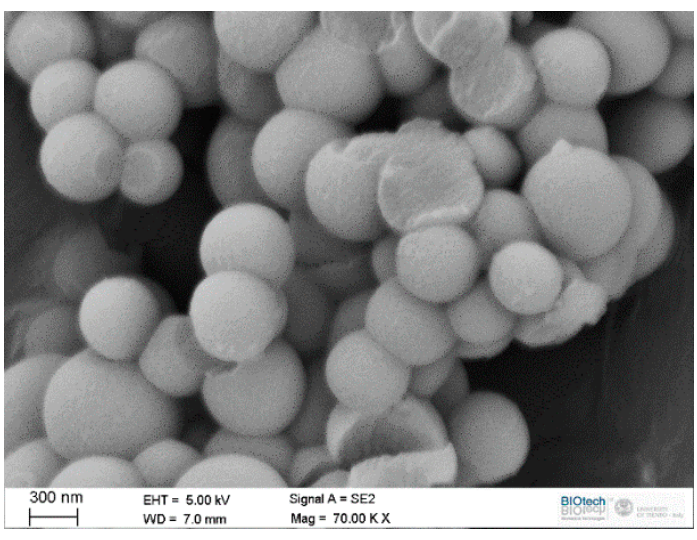

(b)

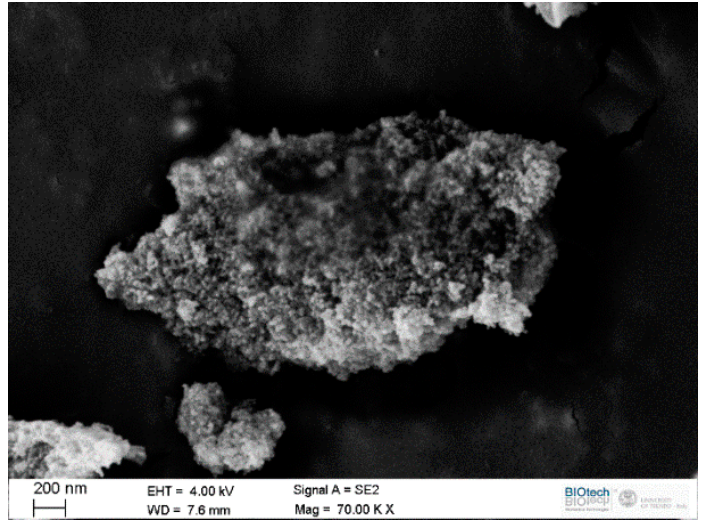

(d)

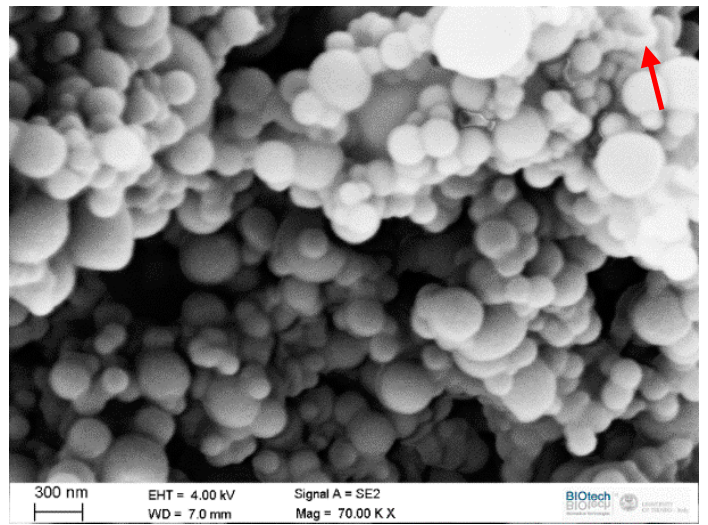

(f)

Figure 2. SEM micrographs of the prepared samples. (a,b) Si, (c,d) MC1, (e,f) MC2. 
The neat organosilica particles ( $\mathrm{Si}$, Figure $2 \mathrm{a}, \mathrm{b}$ ) present a spherical shape, a smooth surface, and dimensions of $606 \pm 110 \mathrm{~nm}$. They are monodispersed with a relatively narrow size distribution in agreement with previous results [32,34]. However, microparticles appear strongly aggregated, as clearly observable at higher magnification in Figure $2 \mathrm{~b}$. For the samples containing microencapsulated docosane, the first manifest difference between MC1 (Figure 2c,d) and MC2 (Figure 2e,f) is the particle size. The sample MC1 is composed of strongly aggregated and extremely small particles, with a diameter of approximately $50 \mathrm{~nm}$. It was not possible to acquire images at higher magnifications, due to the instability of the sample under the electron beam during focusing, and thus the analysis of the particle size was performed manually on a digitally zoomed micrograph. Due to the blurriness of the resulting image, it was difficult to perform an accurate analysis, but the measured diameters fell in the range $35-60 \mathrm{~nm}$. The particles of the sample MC2 are bigger, spherical, and with shape, surface roughness and state of aggregation resembling those of neat organosilica spheres. MC2 particles are smaller than Si ones $(244 \pm 98 \mathrm{~nm})$ and have a higher coefficient of variation. The majority of the capsules are intact, but a core-shell morphology can be observed from the sporadically broken capsules, as indicated with a red arrow in Figure $2 \mathrm{f}$.

\subsubsection{FTIR Spectroscopy on the Microcapsules}

Figure 3 reports the FTIR spectra obtained on the bulk docosane (D), MC1 and MC2 microcapsules and the neat organosilica microparticles (Si).

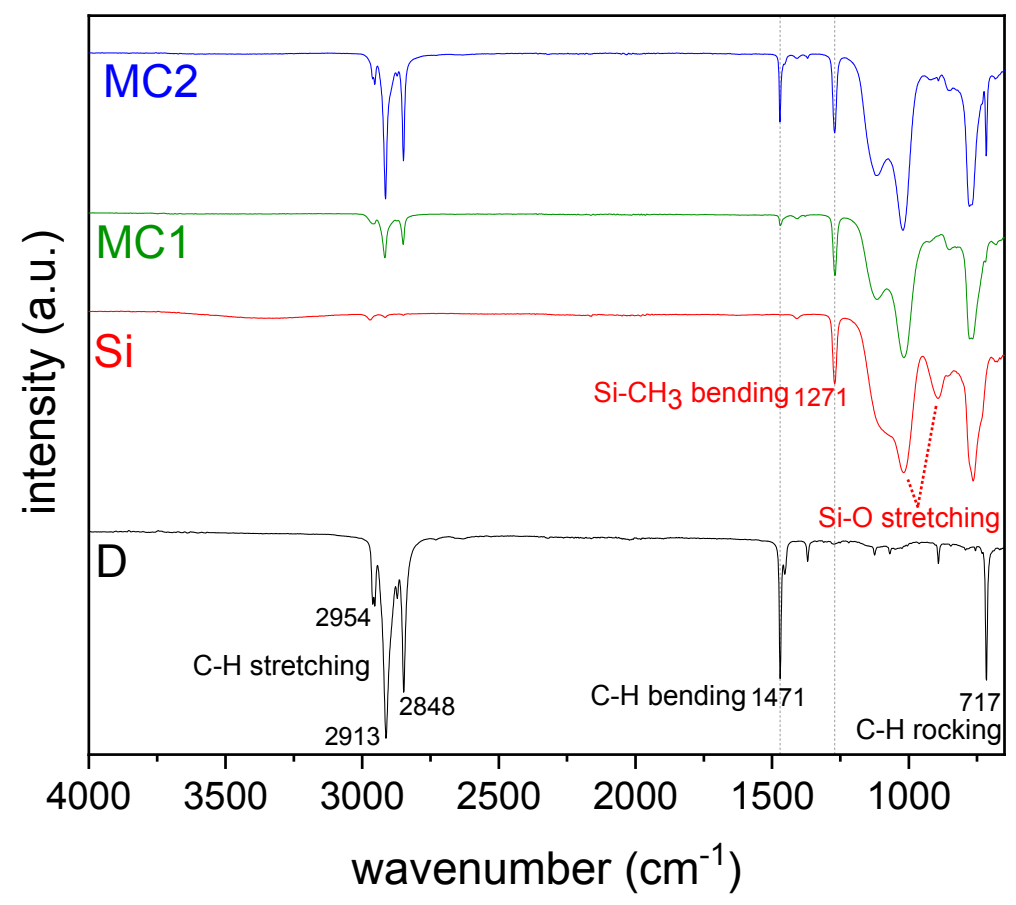

Figure 3. FTIR spectra of the bulk docosane (D), docosane-organosilica core-shell microparticles (MC1 and MC2) and the neat organosilica microparticles (Si).

The spectrum of the neat docosane is characterized by the typical vibrations of methylene groups; the peaks at 2954, 2913, 2872 and $2848 \mathrm{~cm}^{-1}$ can be assigned to the $\mathrm{C}-\mathrm{H}$ bond stretching vibration in $-\mathrm{CH}_{2}$ and $-\mathrm{CH}_{3}$ groups, while the peaks at 1471,1454 and $1370 \mathrm{~cm}^{-1}$ can be attributed to the asymmetric and symmetric bending of $-\mathrm{CH}_{2}$ and $-\mathrm{CH}_{3}$ groups, respectively, and the peak at around $717 \mathrm{~cm}^{-1}$ is due to the rocking vibration of the $-\mathrm{CH}_{2}$ group [32,34]. On the other hand, the sample Si shows the peaks associated with the organosilica network originated from MTES. The small peaks in the interval $3000-2800 \mathrm{~cm}^{-1}$ are related to the stretching vibration of the $\mathrm{C}-\mathrm{H}$ bond in the methyl group, and the peak at $1271 \mathrm{~cm}^{-1}$ is due to the bending vibration of the $\mathrm{Si}-\mathrm{CH}_{3}$ bonds [50]. The two broad bands 
around 1117 and $1021 \mathrm{~cm}^{-1}$ and the weak signal at $924 \mathrm{~cm}^{-1}$ are due to the asymmetric stretching vibrations of siloxane bonds and silanols, respectively [51]. The peak at $853 \mathrm{~cm}^{-1}$ is due to Si-O symmetric stretching and the signal at $777 \mathrm{~cm}^{-1}$ can be attributed to the $\mathrm{Si}-\mathrm{C}$ bond vibration [51]. Both docosane and organosilica signals are present with different relative intensity in the spectra of the two prepared microencapsulated samples, thus proving the presence of the paraffin core in MC1 and MC2. The peaks associated with docosane are more intense in MC2 than in MC1, indicating a higher docosane content in the larger microcapsules. The siloxane band appears narrower in comparison with Si sample, particularly in the case of MC2. From the FTIR analysis, it is possible to make some semi-quantitative considerations based on sharp peaks belonging to the same spectral region. By measuring the intensity ratio of the two peaks indicated with dotted lines in Figure 3, i.e., the signal at $1471 \mathrm{~cm}^{-1}$ related to methylene docosane, and the one at $1271 \mathrm{~cm}^{-1}$ attributed to $\mathrm{Si}-\mathrm{CH}_{3}$ in organosilica, the docosane-to-organosilica molar ratios result of 0.15 and 0.55 for MC1 and MC2, respectively, in agreement with the results of NMR and TGA analyses reported below.

\subsubsection{XRD Analysis}

Figure 4 reports the XRD spectra of the samples D, MC1, MC2, and Si.

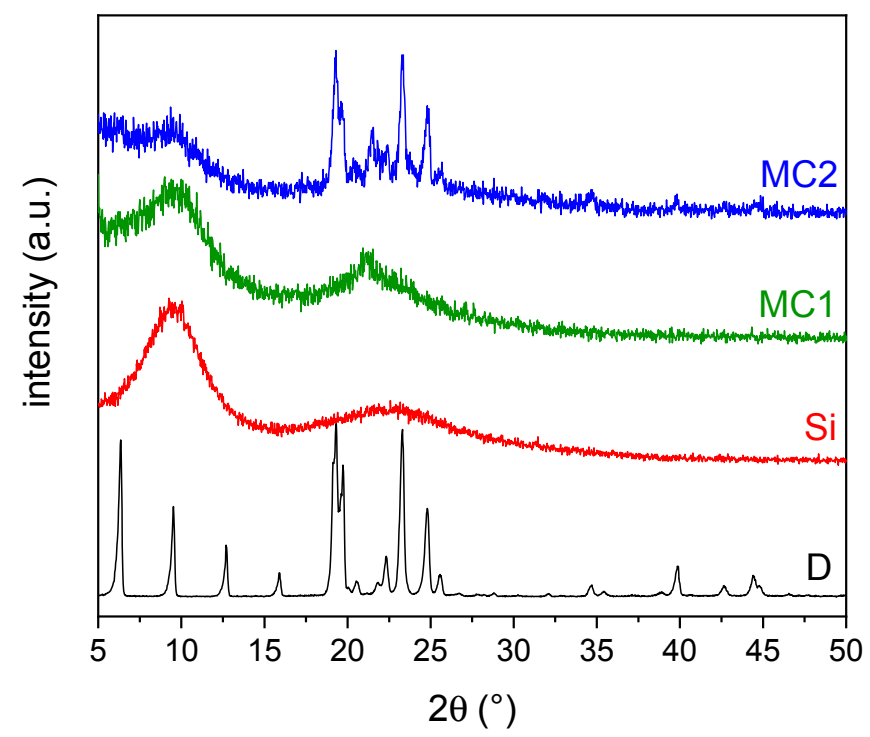

Figure 4. XRD spectra of the bulk docosane (D), MC1 and MC2 microcapsules and the neat organosilica microparticles $(\mathrm{Si})$.

For the spectrum of the neat docosane, the signals can be attributed to the triclinic phase of solid docosane, stable up to approx. $40{ }^{\circ} \mathrm{C}[52,53]$. This phase is characterized by the spatial group $\mathrm{P} \overline{1}$, generally indicated as $\gamma_{0}(\mathrm{C} 22)$, with cell parameters $\mathrm{a}=4.2805 \AA, \mathrm{b}=4.8212 \AA, \mathrm{c}=28.2877 \AA$, $\alpha=91.14^{\circ}, \beta=94.63^{\circ}, \gamma=106.39^{\circ}$. On the other hand, the Si spectrum displays the typical diffraction pattern of the amorphous MTES-derived organosilica, with two broad halos located at around $10^{\circ}$ and $23^{\circ}[12,30,31]$.

The XRD spectrum of the microcapsules MC1 resembles that of the neat organosilica, and the diffraction pattern of the docosane phase is not detectable unless a broad and less intense peak centered at $21^{\circ}$. On the contrary, in the spectrum of MC2 both the broad halos of the organosilica phase and the sharp peaks of the docosane phase, especially between $18^{\circ}$ and $28^{\circ}$, are clearly detectable, whereas the peaks at lower angles are not visible. In this spectrum, the docosane reflection at $21.4^{\circ}$ is relatively more intense with respect to the spectrum of $\mathrm{D}$. This may suggest the presence of a different solid crystallographic phase, the so-called rhombohedral rotator phase R-II, which in normal conditions is stable near the melting temperature [45]. This rotator phase is a crystalline mesostate with a rotational degree of freedom along the chain axis [19]. This result, therefore, suggests that the confinement of the 
paraffin chains inside the organosilica shells induces a structural disorder; in fact, the absence of (001) peaks in MC2 spectrum, located at angles lower than $18^{\circ}$, can be attributed to the disappearance of the lamellar ordering of the $\gamma_{0}\left(\mathrm{C}_{22}\right)$ structure, whereas the lateral arrangements of the chains remain unchanged (peaks located at angles greater than $18^{\circ}$ ) [54]. On the other hand, the reduction of the particle size in MC1 sample, as revealed by SEM analysis, leads to a more pronounced distorted situation, and only the signal of the rotator state appears with a shift towards lower angle than for MC2 sample. This evidence suggests that the degree of confinement of docosane in organosilica microcapsules can be related to the particle size [54].

\subsubsection{Solid-State NMR Analysis}

Solid-state NMR analysis was performed to deeply investigate the microstructure, the morphology and the confinement effect of the different microcapsules. Figure $5 \mathrm{a}, \mathrm{b}$ shows the ${ }^{13} \mathrm{C}$ and ${ }^{29} \mathrm{Si} \mathrm{CP}-\mathrm{MAS}$ spectra of the neat docosane, the two microencapsulated PCMs, and the organosilica particles.

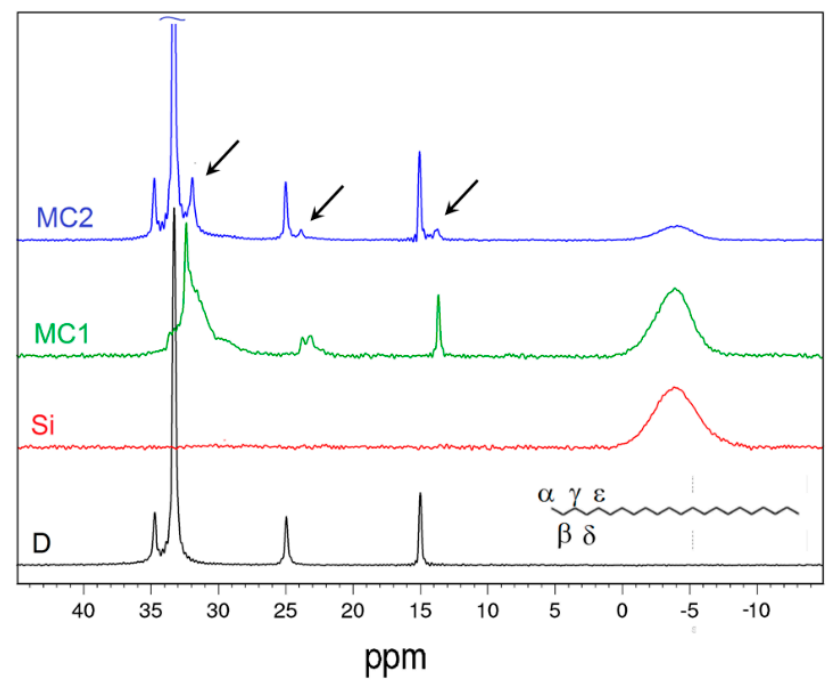

(a)

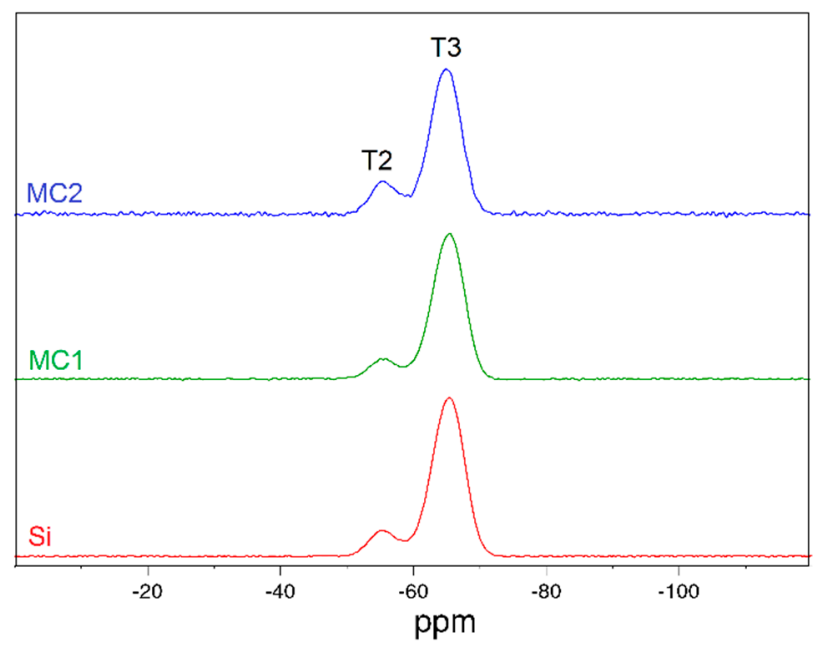

(b)

Figure 5. NMR spectra of docosane (D), MC1 and MC2 microcapsules and the neat organosilica microparticles (Si): (a) ${ }^{13} \mathrm{C} C \mathrm{CP}$-MAS spectra with docosane carbon labeling and arrows to highlight rotator phase signals; $(\mathbf{b}){ }^{29} \mathrm{Si} \mathrm{CP}-\mathrm{MAS}$ spectra. 
The spectrum of bulk docosane in Figure 5a shows the typical signals of the n-alkanes, associated with the first four carbon atoms in the chain (indicated as $\alpha, \beta, \gamma, \delta$ in the structural scheme, Figure 5a), while the chemical shifts are not anymore resolvable from the fifth $(\varepsilon)$ carbon atom on [55]. For the neat organosilica microcapsules $(\mathrm{Si})$, the only signal is found at approx. $-4 \mathrm{ppm}$ and it is due to the methyl carbon atoms linked to silicon, while the absence of signals associable to the ethoxy groups indicates the completion of MTES hydrolysis [51]. Together with all the paraffin and MTES signals, the docosane phase in the sample MC2 shows also some minor upfield shifted peaks (approx. $2 \mathrm{ppm}$ ) close to the $\alpha, \beta$ and $\varepsilon$ signals, indicated with arrows in Figure 5a, which can be associated with $\alpha$, $\beta$ and $\varepsilon$ methylene groups in a different environment. Interestingly, in the spectrum of MC1, the chemical shift of docosane signals fits with the weak upfield resonances of MC2 spectrum, and there are no signals in the original positions. The upfield shifted resonances can be due to the presence of the rotator phase, already mentioned in paragraph 3.1.4, or also to the $\gamma$-gauche effect near the chain ends, which causes a non-uniform distribution of the conformational disorder, thereby broadening the peaks [56]. This behavior could be attributed to the confinement effect of the docosane inside the capsules, and the fact that it is more evident for the smaller (MC1) capsules supports this hypothesis [57] in agreement with XRD conclusions. In this sense, it could be useful to evaluate the signals of the ${ }^{13} \mathrm{C}$ proton-decoupled MAS spectrum (Figure S1 and related discussion, see Supplementary Materials). As the spin-lattice relaxation times of the various carbon atoms are remarkably different from each other (e.g., for $\alpha-C$ it is $1.2 \mathrm{~s}$, for $\beta-C 16 \mathrm{~s}$, for $\gamma-C$ and $\varepsilon-C>700 \mathrm{~s}$ ), with the selected experimental parameters it is possible to make a quantitative comparison among the methyl groups. From the ratio between the areas of $\mathrm{H}_{3} \mathrm{C}-\mathrm{Si}(-4 \mathrm{ppm})$ and $\mathrm{H}_{3} \mathrm{C}-\mathrm{CH}_{2}(14 \mathrm{ppm})$ signals, the molar ratio organosilica/docosane can be deduced, considering that the signal at $-4 \mathrm{ppm}$ counts for one carbon atom and that at $14 \mathrm{ppm}$ for two. The results of this calculation give docosane-to-organosilica molar ratios of 0.09 and 0.53 for MC1 and MC2, respectively. What is immediately evident is that for the sample MC1 the silica fraction is approx. 6 times higher than for MC2, which is in good agreement with both the ratios calculated from FTIR peaks (Section 3.1.3) and the DSC results (Section 3.1.6). Moreover, by integrating the area of $\alpha$ and $\alpha^{\prime}$ signals, it is possible to estimate that the rotator phase (represented by $\alpha^{\prime}$ ) is the $20 \%$ of all the encapsulated alkane for sample MC2, while for the MC1 it represents the $100 \%$.

Furthermore, through molecular dynamics NMR experiments (see Figure S2 in Supplementary Materials for details), and especially from the evaluation of ${ }^{13} \mathrm{C}$ spin-lattice relaxation times $\left(\mathrm{T} 1_{\mathrm{C}}\right)$, it is possible to prove that the two detected phases represent respectively a free bulk paraffin fraction and a docosane fraction interacting with the inner silica shell, since the interaction causes a remarkable reduction of $\mathrm{T} 1_{\mathrm{C}}$. A similar effect was already observed by Inoue et al. [58], who studied the behavior of polyethylene on silica surfaces and imputed the constraints of the molecular motions of the polymer chains to the interaction with the silica surface. As evidenced by the XRD measurements, the inclusion can cause an alteration of the crystalline structure. This effect was already mentioned by Okazaky [56], who studied through T1 analysis the different behavior of even and odd alkanes. As a matter of fact, despite the very long $\mathrm{T} 1_{\mathrm{C}}$ of main chain carbons of pure docosane measured by Okazaky, the present samples show a reduced and capsule size-dependent $\mathrm{T} 1$ value for main chain methylenes, whereas it is practically unchanged for methyls (Table S1). No effects due to interaction can be detected for silica methyls, as also showed by Okazaky's samples. The overall size-dependent $\mathrm{T} 1_{\mathrm{C}}$ reduction is a proof of the effective paraffin inclusion and the lower values shown by $\alpha^{\prime}$ and $\beta^{\prime}$ with respect to $\alpha$ and $\beta$ further indicate the interaction of a docosane fraction with the silica shell, which leads to the alteration of the crystal structure in perfect agreement with XRD conclusions.

Finally, Figure $5 \mathrm{~b}$ shows the ${ }^{29} \mathrm{Si} \mathrm{CP}-\mathrm{MAS}$ of the samples MC1, MC2, and $\mathrm{Si}$, to investigate the degree of condensation of the organosilica phase. All the samples show the signals of the $\mathrm{T}^{2}$ $\left(\mathrm{R}-\mathrm{Si}(\mathrm{OSi})_{2}(\mathrm{OH})\right)$ and $\mathrm{T}^{3}\left(\mathrm{R}-\mathrm{Si}(\mathrm{OSi})_{3}\right)$ units, at $-55.7 \mathrm{ppm}$ and $-65.6 \mathrm{ppm}$, respectively [51], and the intensity ratios are comparable in the three cases, which implies that the presence of docosane and CTAB surfactant does not influence MTES hydrolysis-condensation process. The quantitative analysis was performed on the ${ }^{29} \mathrm{Si}$ proton-decoupled MAS spectra (not reported) and confirms the trends 
observed in the CP-MAS spectra, being the condensation levels approx. $96 \%$ for the sample Si and $94 \%$ for the sample MC2.

\subsubsection{DSC Analysis of the Microcapsules}

Figure 6a shows the DSC thermograms of the samples $\mathrm{Si}, \mathrm{D}, \mathrm{MC} 1$, and $\mathrm{MC} 2$. The neat organosilica does not manifest any thermal transition in the considered temperature interval. On the other hand, in the heating scan, all the samples containing docosane experience the melting phase change, visible as a single broad peak at the adopted heating scan $\left(10^{\circ} \mathrm{C} / \mathrm{min}\right)$.

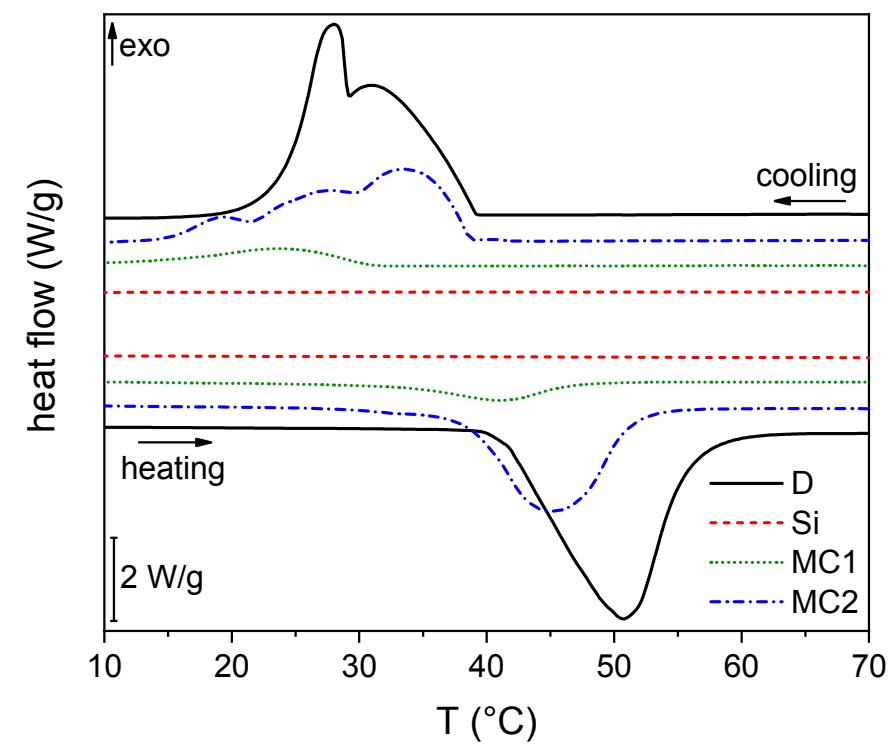

(a)

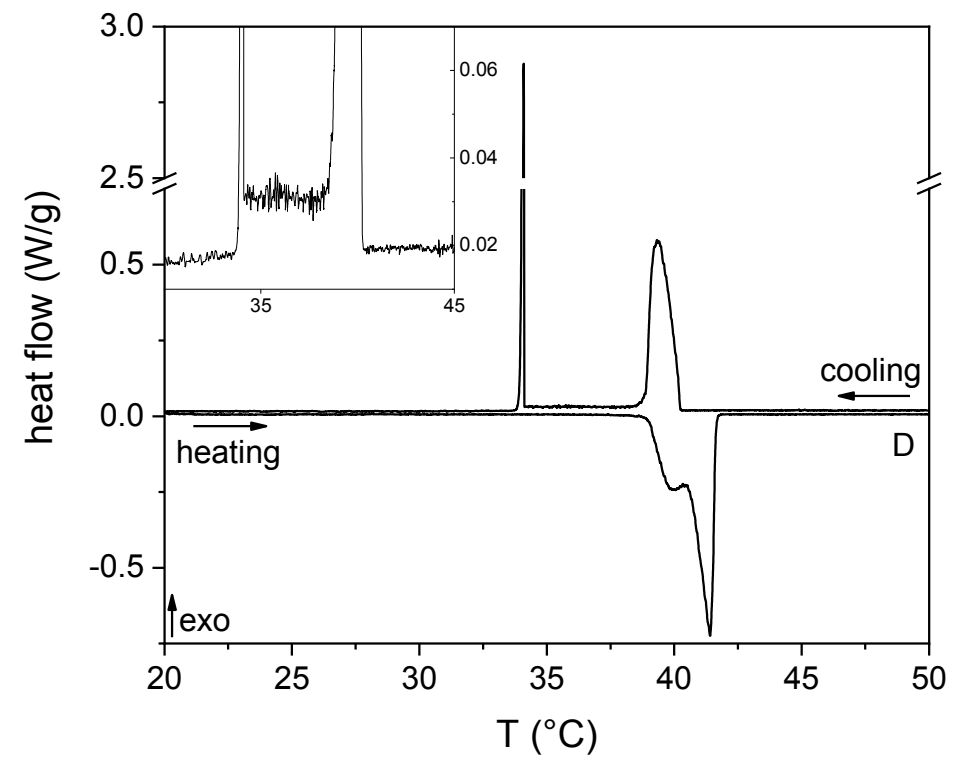

(b)

Figure 6. Cont. 


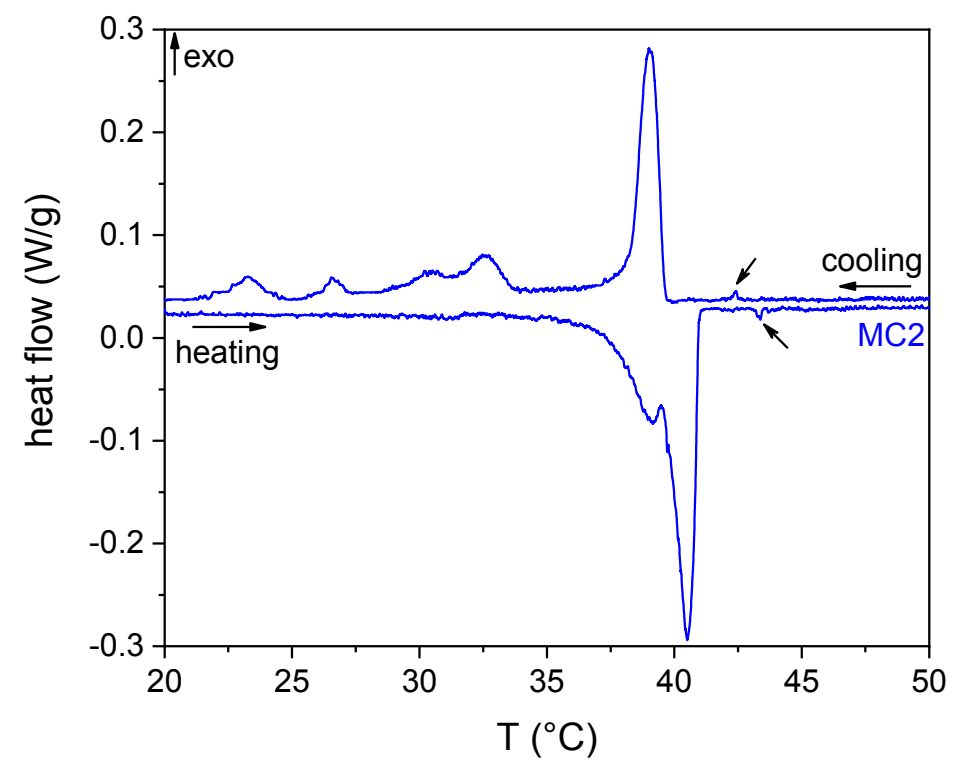

(c)

Figure 6. (a) DSC thermograms of the bulk (D) and microencapsulated (MC1 and MC2) docosane and the neat organosilica microparticles (Si). The first heating scans and the cooling scans are reported. (b) DSC thermogram of the neat docosane acquired at $0.2^{\circ} \mathrm{C} / \mathrm{min}$ (heating and cooling scan). (c) DSC thermogram of the microcapsules $\mathrm{MC} 2$ acquired at $0.2^{\circ} \mathrm{C} / \mathrm{min}$ (heating and cooling scan).

The data reported in Table 3 show that the peak melting temperature $\left(T_{m}\right)$ measured on the microcapsules is lower than that of the neat docosane, and this is more evident for the smaller (MC1) than for the bigger (MC2) capsules. This effect, also reported by other literature studies [29-31,33,59-61], can be ascribed to the fact that the confinement in a small volume hinders the crystallization, but in this specific case also to the interaction of docosane with the inner shell surface, which limits the chain mobility as evidenced by NMR studies (see Section 3.1.5). This hypothesis is supported by the reduction in the melting enthalpy, which is more evident for the smaller capsules presenting a higher surface-to-volume ratio. The same effect is at the basis of the reduction in the peak crystallization temperature for the sample $\mathrm{MC} 1$; as the paraffin domains are confined in smaller volumes, a higher supercooling degree is needed to initiate the crystallization. This phenomenon must be taken into account when designing a microencapsulated PCM, as it could change its application temperature interval. The cooling scans are characterized by the presence of several peaks. The neat docosane shows two peaks, the first $\left(33.5^{\circ} \mathrm{C}\right)$ related to the liquid-solid phase change, and the second $\left(28.5^{\circ} \mathrm{C}\right)$ associated with a solid-solid transition [62], while the microcapsules show several peaks, visible especially in the sample MC2, which can be due to confinement effect and the presence of different crystalline phases. The measured phase change enthalpies are reported in Table 3 . The neat docosane develops $234.2 \mathrm{~J} / \mathrm{g}$, and the melting enthalpies measured on MC1 and MC2 provide information about the docosane fraction in each sample, described by the efficiency $(\eta)$ reported in Table 3 . The sample MC2 contains approx. $60 \%$ of docosane, while the PCM fraction decreases to $14 \%$ for MC1. These data are in good agreement with the NMR (see Section 3.1.5) and TGA (see Section 3.1.7).

Figure $6 \mathrm{~b}, \mathrm{c}$ reports the DSC thermograms of D and MC2 acquired at $0.2{ }^{\circ} \mathrm{C} / \mathrm{min}$. As the lower heating rate allows a better resolution of the signals, the neat docosane (Figure $6 \mathrm{~b}$ ) shows two endothermic peaks in the heating scan, one (at lower temperature) associated with the solid-solid transition from the crystalline phase to the rotator phase, and the other due to the solid-liquid phase transition, in good agreement with the detailed investigation performed by Wang et al. [62]. The cooling scan shows two sharp peaks with a broad halo in between, which is better visible from the inset plot. Following Wang's analysis, the peak at higher temperature can be attributed to the transition from the liquid state to the rotator phase, the broad halo is related to the rotational action of $\mathrm{CH}_{2}$ bonds, 
and the last sharp peak due to the last solid-solid transition, which ends with the formation of an ordered crystalline phase. The encapsulated docosane MC2 shows the same two peaks as the sample $\mathrm{D}$ in the heating scan, but at a slightly lower temperature, and at least five intense peaks in the cooling scan. This implies a different crystallization behavior due to confinement and interaction with the organosilica shell. A very small peak (indicated with arrows on Figure 6c) can also be observed both on heating and on cooling. This is probably due to the surface freezing phenomenon, i.e., to the fusion/crystallization of a monolayer formed on the surface of liquid docosane, observable here due to the high surface-to-volume ratio of the microencapsulated docosane and not normally observable on bulk samples [62].

Table 3. Main results of the DSC tests on the bulk (D) and microencapsulated (MC1 and MC2) docosane. The table reports data of the phase change temperatures and enthalpies, as well as the encapsulation efficiency.

\begin{tabular}{lccccc}
\hline \multicolumn{1}{c}{ Sample } & $\boldsymbol{T}_{\boldsymbol{m}}\left({ }^{\circ} \mathrm{C}\right)$ & $\boldsymbol{T}_{\boldsymbol{c}}\left({ }^{\circ} \mathrm{C}\right)$ & $\Delta \boldsymbol{H}_{\boldsymbol{m}}(\mathrm{J} / \mathrm{g})$ & $\Delta \boldsymbol{H}_{\boldsymbol{c}}(\mathrm{J} / \mathrm{g})$ & $\eta(\%)$ \\
\hline D & 46.2 & 33.5 & 234.6 & -234.2 & 100 \\
MC1 & 41.2 & 25.1 & 33.0 & -32.9 & 14.1 \\
MC2 & 43.8 & 34.5 & 142.7 & -141.4 & 60.6
\end{tabular}

$T_{m}, T_{c}=$ melting and crystallization temperatures of the PCM; $\Delta H_{m}, \Delta H_{c}=$ melting and crystallization enthalpies of the PCM; $\eta=$ encapsulation efficiency.

The DSC tests at different heating scans were also performed to determine the apparent activation energy $\left(E_{a}\right)$ of the phase transition of the bulk and microencapsulated docosane. The results are reported in Figure S3 in Supplementary Materials. The value of $E_{a}$ for docosane melting is $501 \mathrm{~kJ} / \mathrm{mol}$, in good agreement with similar systems [63]. Despite the not negligible error bands, related to the values of R2 lower than 1 in the linear regressions of the phase change temperatures, it can be appreciated that the values of $E_{a}$ increase upon encapsulation, probably due to steric effects and interaction with the capsule shell.

\subsubsection{TGA Analysis of the Microcapsules}

Figure 7a,b shows the TGA thermograms on the prepared microcapsules, while the most important results are displayed in Table S2.

The bulk docosane undergoes a single-step thermal degradation with $T_{p}^{D}$ at $291{ }^{\circ} \mathrm{C}$, while the neat organosilica is thermally stable until approx. $500^{\circ} \mathrm{C}$. Both the degradation steps are present in the samples MC1 and MC2, but the derivative peak temperatures are of some degrees lower than those of the neat samples, which was already reported in the literature, especially for the PCM phase [31]. From the amplitude of the degradation step of docosane, it is possible to estimate the docosane weight fraction for the samples MC1 and MC2, which are reported in Table S2. The fraction of docosane calculated for MC2 is 65\%, and this is in good agreement with the DSC results, while that determined for $\mathrm{MC1}, 26 \%$, is slightly higher than that calculated via DSC, and this can be due to sample inhomogeneity, but also to the fact that the crystallinity degree of the docosane encapsulated in small microcapsules, such as the sample MC1, is lower than that of the free docosane, and thus the developed enthalpy is lower than expected, which is in agreement with the XRD results. It is worth noting that the docosane weight content calculated by TGA is in good agreement with the molar amount estimated by both FTIR and NMR analyses.

\subsection{Characterization of the Epoxy-Based Matrices and Laminates}

The characterization previously described highlights the higher melting enthalpy and the overall better performance of the capsules MC2. Therefore, this PCM was used in combination with an epoxy matrix and continuous carbon fibers to produce multifunctional composites. An extensive 
characterization was performed to assess the influence of the microcapsules on the properties of the neat epoxy and the epoxy/carbon laminate. The results of this characterization are discussed hereafter.

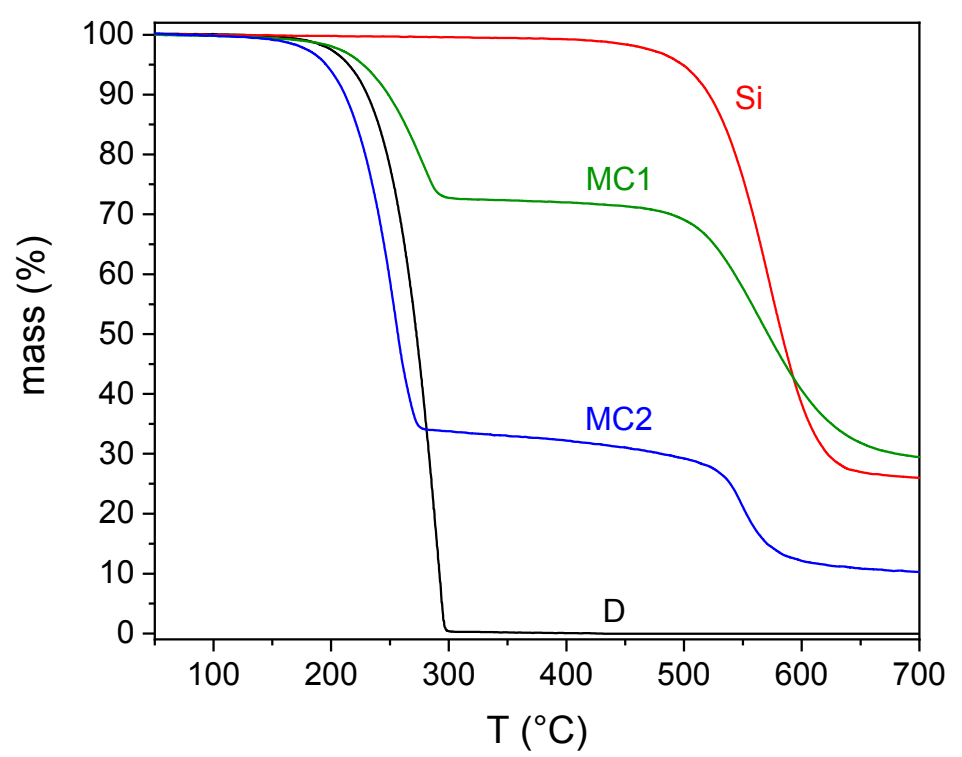

(a)

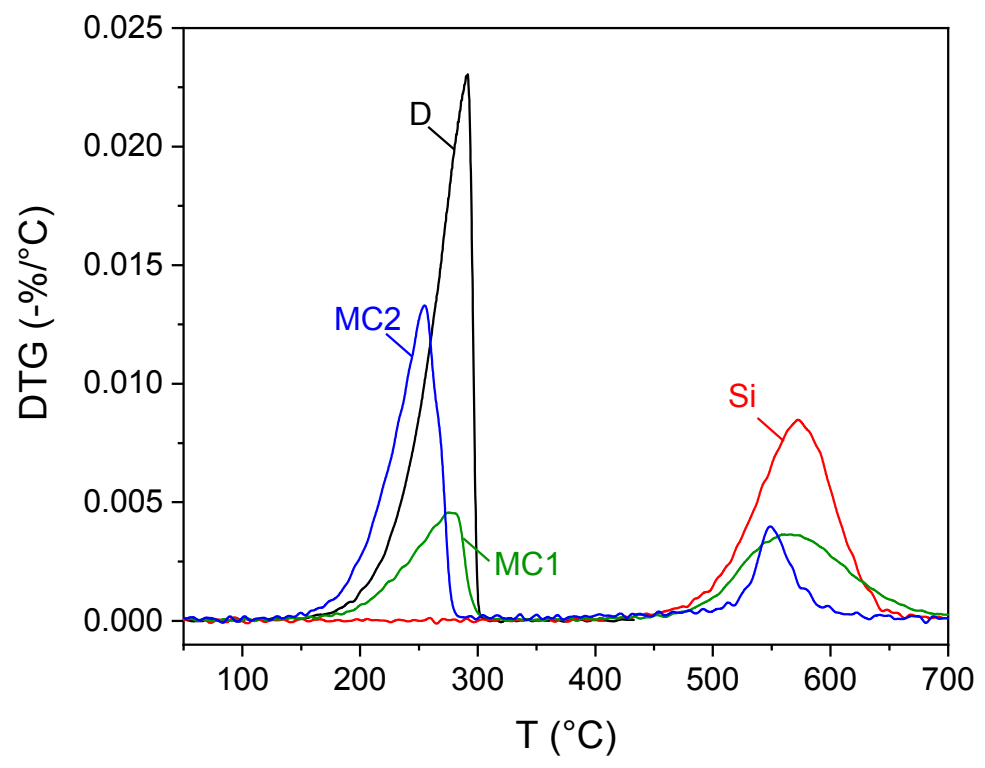

(b)

Figure 7. TGA thermograms of the bulk (D) and microencapsulated (MC1 and MC2) docosane and the neat organosilica microparticles (Si). (a) mass; (b) mass loss derivative (DTG).

\subsubsection{SEM Microscopy on the Matrices and Laminates}

Figure 8a-d shows the SEM micrographs of the cryofracture surface of the EP-MC2 matrix and EP-MC2-CF composite. 


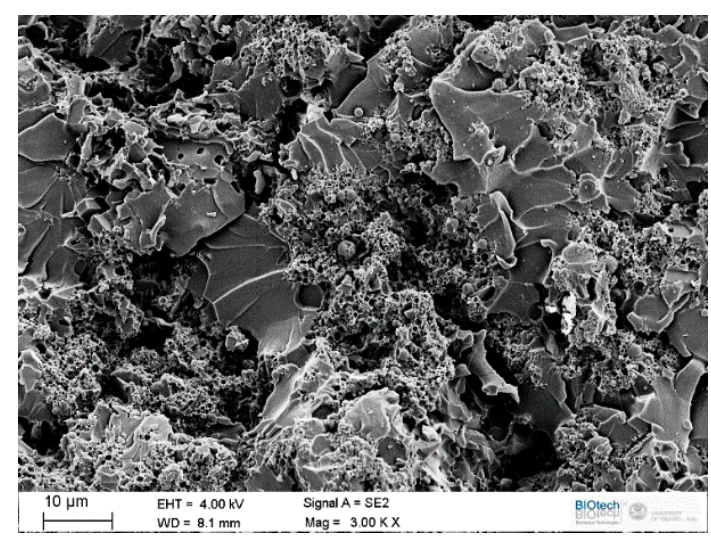

(a)

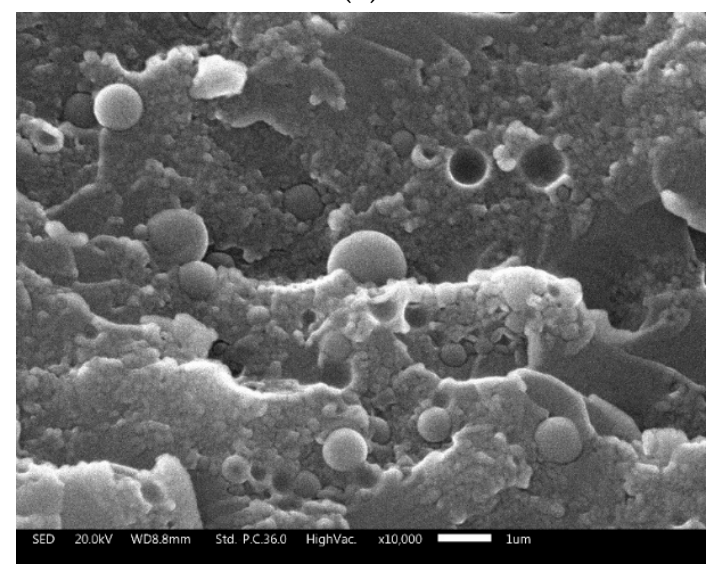

(c)

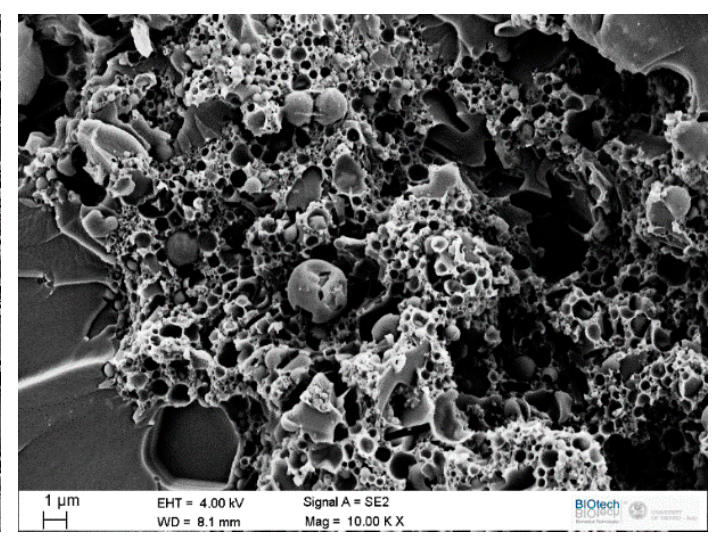

(b)

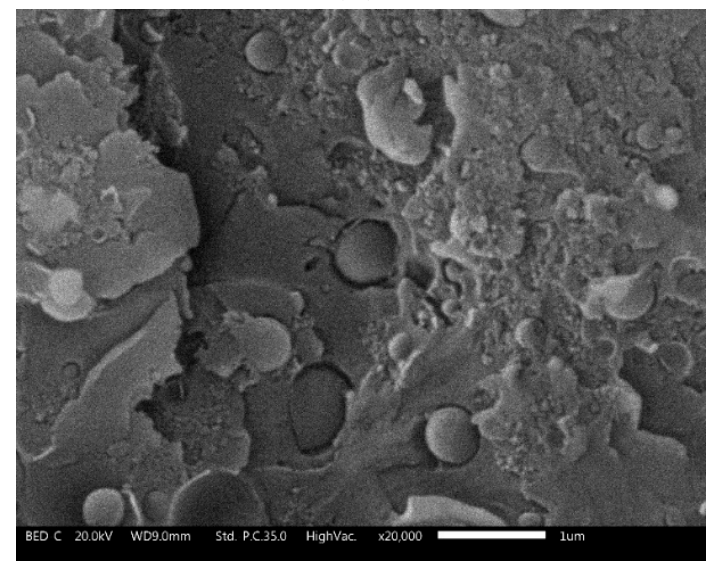

(d)

Figure 8. SEM micrographs of the samples EP-MC2 (a,b) and EP-MC2-CF (c,d).

The micrographs of the sample EP-MC2 show the presence of aggregates and agglomerates, which have already been observed in the micrographs of the neat particles (see Figure 2). Although the state of aggregation of PCM micro- or nano-capsules is a very important parameter, it is not commonly described in the research articles dealing with the synthesis of microencapsulated PCM, and therefore the results of this study can hardly be compared to previous work. On the other hand, agglomerates in the composites could be avoided by improving the mixing conditions. Although the attempts made so far, which included solvent-assisted dispersion, have not been successful, further effort will be made to improve the dispersion of the microcapsules in the epoxy matrix. It can also be noticed that the capsule-matrix adhesion is not excellent, as the fracture is adhesive and occurs at the interface. The use of another silane precursor instead of MTES, with a different functional group (e.g., aminopropyltriethoxysilane, APTES), could be beneficial to overcome this problem and improve the chemical compatibility between the epoxy and the capsule shells. The same conclusions can be made for the micrographs of the composites, which focus on the capsule-rich interlaminar region.

\subsubsection{DSC on the Matrices and Laminates}

The DSC thermograms of the epoxy matrix with and without microcapsules (EP and EP-MC2) are reported in Figure 9a. The sample EP presents a single glass transition at approx. $94{ }^{\circ} \mathrm{C}$, while the thermogram of the sample EP-MC2 also shows the peaks associated with the phase change of the microencapsulated docosane. As shown in Table S3, the developed phase change enthalpy is approx. $14 \mathrm{~J} / \mathrm{g}$, and from this value the experimental weight fraction of docosane and MC2 can be estimated as $6.2 \mathrm{wt} \%$ and $10.2 \mathrm{wt} \%$, respectively, which matches the nominal weight fraction of MC2 (10 $\mathrm{wt} \%)$ and the fraction of docosane in the MC2 microcapsules (approx. $60 \mathrm{wt} \%$ ). This implies that the TES 
properties of the microcapsules are also preserved after the production process needed to embed them in an epoxy matrix. The same analysis was conducted on the carbon fiber laminates, whose DSC thermograms are reported in Figure 9b. Once again, the PCM-filled sample shows peaks related to the phase transition of the filler, and an experimental mass fraction of docosane of $4.1 \mathrm{wt} \%$ can be calculated from the developed enthalpy. As reported in Table S3, the melting and crystallization peak temperatures of the laminate are lower and higher, respectively, than those of the sample EP-MC2, which can be due to the higher thermal conductivity induced by the carbon fibers.

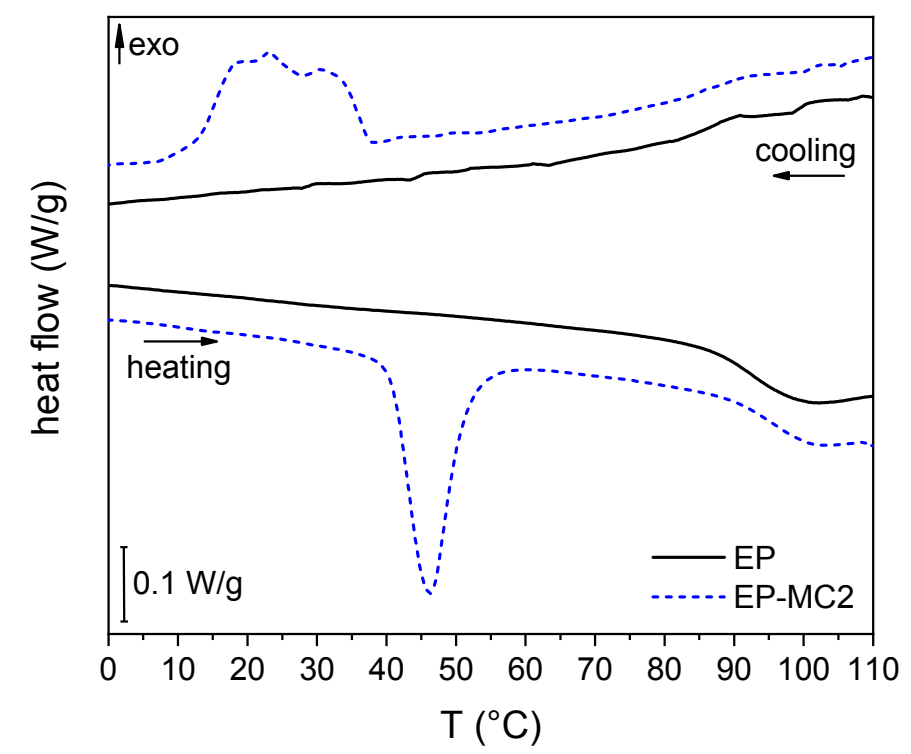

(a)

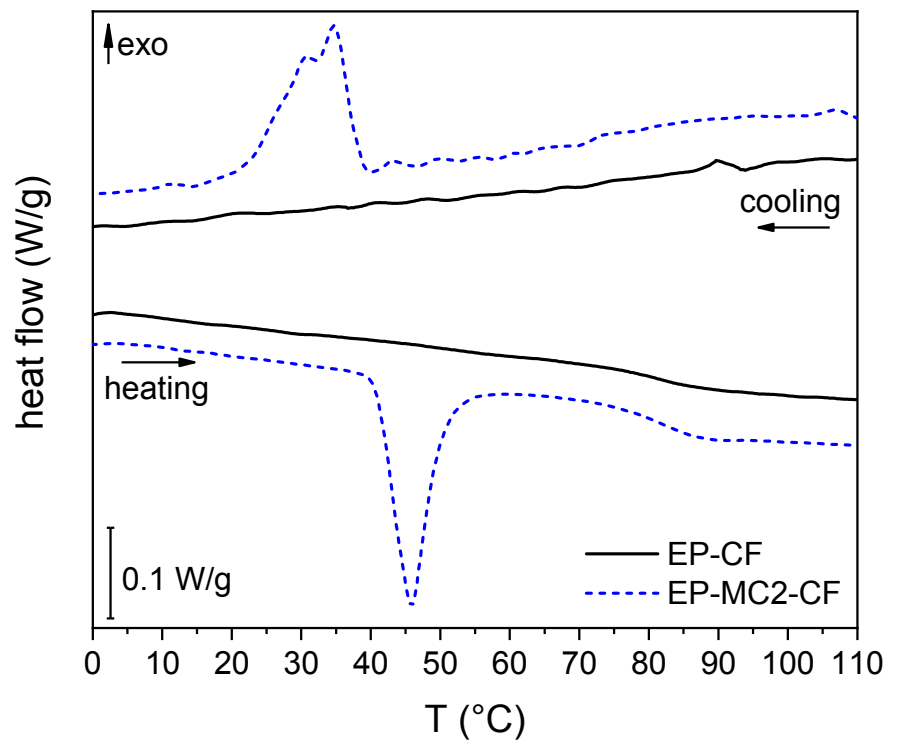

(b)

Figure 9. DSC thermograms of the prepared epoxy-based matrices and laminates. The first heating scans and the cooling scans are reported. (a) EP and EP-MC2; (b) EP-CF and EP-MC2-CF.

\subsubsection{TGA Analysis and Fraction of the Constituents}

The investigation of the weight fraction of the constituents in the composites was made by means of TGA analysis and the Archimedes' balance test, which allowed the measurement of the density 
and porosity. The TGA results are reported in Figure 10a,b and Table S4. The neat epoxy resin (EP) degrades at $368^{\circ} \mathrm{C}$ in a single step, also found in all other samples, while the two samples containing MC2 also present the degradation step of docosane, at $210^{\circ} \mathrm{C}$. The residues at the end of the test are mostly due to carbon fibers, but also partly to the shells of the microcapsules and residual char of the epoxy.

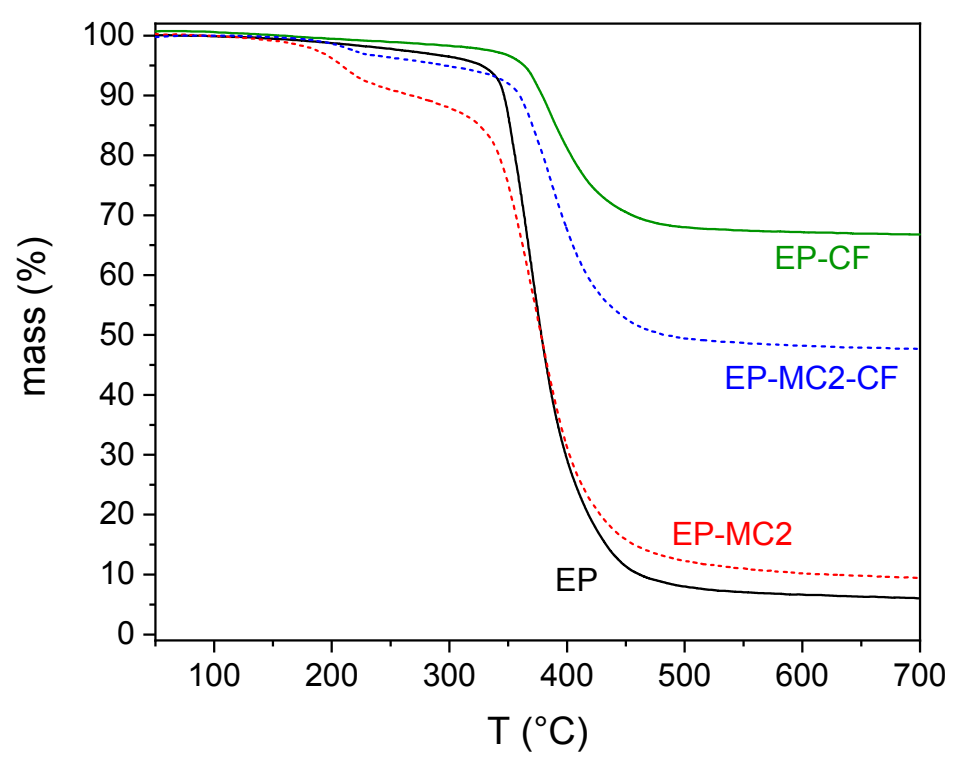

(a)

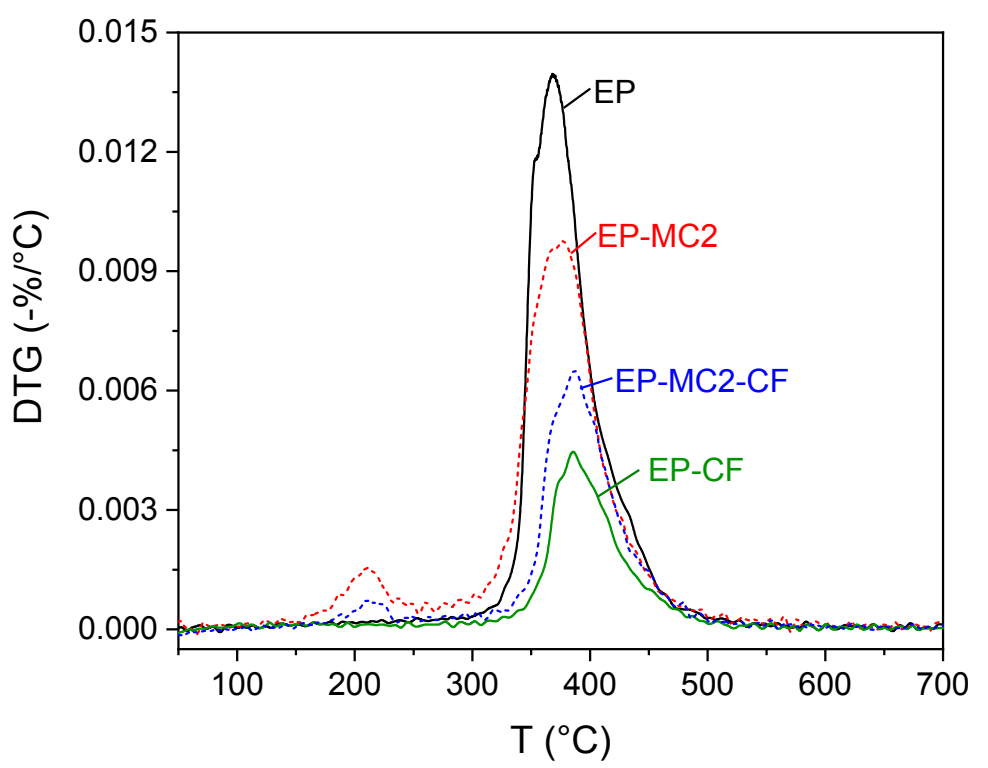

(b)

Figure 10. TGA thermograms of the epoxy-based matrices EP and EP-MC2, and on the laminates EP-CF and EP-MC2-CF. (a) mass; (b) mass loss derivative (DTG).

From the comparison of the residues at $700{ }^{\circ} \mathrm{C}$, also reported in Table 4 , an experimental fiber weight fraction was determined for the laminates. It can be observed that this value is higher for the EP-CF laminate. This could be attributed to the increase in the matrix viscosity produced by the microcapsule that might prevent the matrix from flowing out of the fabric during the laminate fabrication, thereby favoring a high final matrix weight fraction. With the experimental weight distribution of the 
composites and the density of each constituent, a theoretical density was calculated and compared with the experimental density obtained via Archimedes' balance technique. This comparison allowed the calculation of a pore volume fraction, which is comparable for the two laminates and compatible with the adopted hand layup process. Moreover, from the degradation step of docosane, an experimental weight fraction of docosane was determined for the MC2-containing samples. It resulted as $7.6 \mathrm{wt} \%$ for the matrix EP-MC2 and $4.3 \mathrm{wt} \%$ for the laminate EP-MC2-CF. These values are slightly lower than those determined via DSC, but still in the same range.

Table 4. Density and weight fraction of the constituents of the epoxy-based matrices and laminates from the TGA and Archimedes' balance tests.

\begin{tabular}{|c|c|c|c|c|c|c|c|}
\hline Sample & $\begin{array}{l}R_{700^{\circ} \mathrm{C}} \\
(\mathbf{w t} \%)\end{array}$ & $\begin{array}{c}\omega_{f} \\
(w t \%)\end{array}$ & $\begin{array}{c}\rho_{\exp } \\
\left(\mathrm{g} / \mathrm{cm}^{3}\right)\end{array}$ & $\begin{array}{c}\rho_{t h} \\
\left(\mathrm{~g} / \mathrm{cm}^{3}\right)\end{array}$ & $\begin{array}{c}\vartheta_{v} \\
(\operatorname{vol} \%)\end{array}$ & $\begin{array}{l}R_{260^{\circ} \mathrm{C}} \\
(\mathbf{w t} \%)\end{array}$ & $\begin{array}{l}\omega_{D}^{T G A} \\
(w t \%)\end{array}$ \\
\hline $\mathrm{EP}$ & 6.0 & - & $1.179 \pm 0.001$ & - & - & 97.4 & 0 \\
\hline EP-MC2 & 9.4 & - & $1.089 \pm 0.013$ & - & - & 90.1 & 7.6 \\
\hline $\mathrm{EP}-\mathrm{CF}$ & 66.8 & 64.7 & $1.454 \pm 0.006$ & 1.508 & 3.8 & 98.7 & 0 \\
\hline EP-MC2-CF & 48.2 & 42.8 & $1.269 \pm 0.008$ & 1.306 & 2.7 & 95.9 & 4.3 \\
\hline
\end{tabular}

$R_{700^{\circ} \mathrm{C}}=$ residual mass at the end of the test $\left(700^{\circ} \mathrm{C}\right) ; \omega_{f}=$ fiber weight fraction; $\rho_{\exp }=$ experimental density, measured through Archimedes' balance method; $\rho_{t h}=$ theoretical density; $\vartheta_{v}=$ pores volume fraction; $R_{260^{\circ} \mathrm{C}}=$ residual mass at $260^{\circ} \mathrm{C}$, after the degradation of docosane; $\omega_{D}^{T G A}=$ weight fraction of docosane.

\subsubsection{Three-Point Bending Test}

The results of the investigation of the mechanical properties are reported in Figure 11. Comparing the samples EP and EP-MC2, the presence of microcapsules decreases the elastic modulus of the epoxy resin only slightly, but it dramatically impairs the properties at break, i.e., the flexural strength and the strain at break. This can be due to the presence of microcapsules aggregates and agglomerates, as observed in the SEM micrographs. A similar trend is also observed in the composites, and although the decrease in mechanical properties are also due to the decrease in the fiber volume fraction, it can be concluded that the introduction of a PCM is not beneficial for the mechanical properties, as was already observed in our previous studies on PCM-enhanced composites [36-38,40,41].

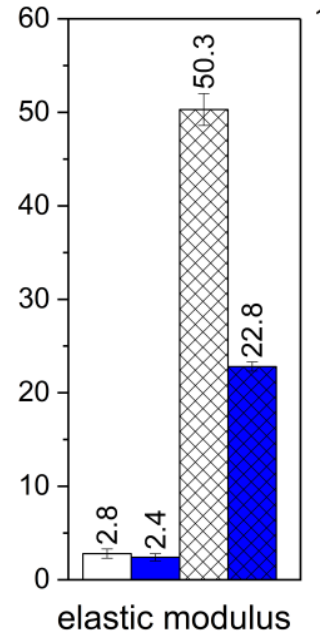

(GPa)

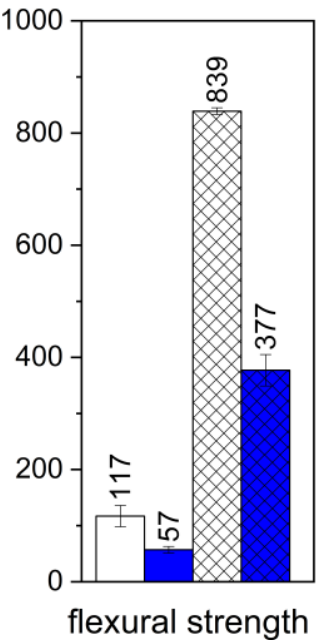

(MPa)

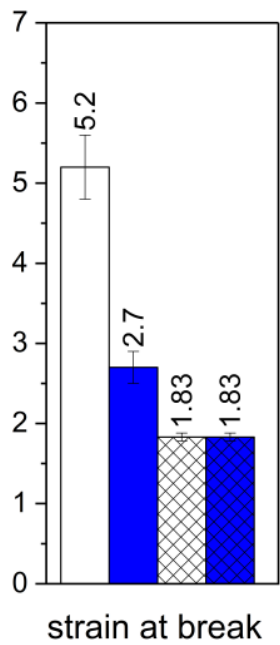

(\%)

Figure 11. Main results of the three-point bending tests on the epoxy-based matrices EP and EP-MC2, and on the laminates EP-CF and EP-MC2-CF.

\subsubsection{DMA Analysis}

The mechanical and thermo-mechanical properties of the laminates were also assessed through DMA, and the results of the characterization are shown in Figure 12a-c and Table S5. 


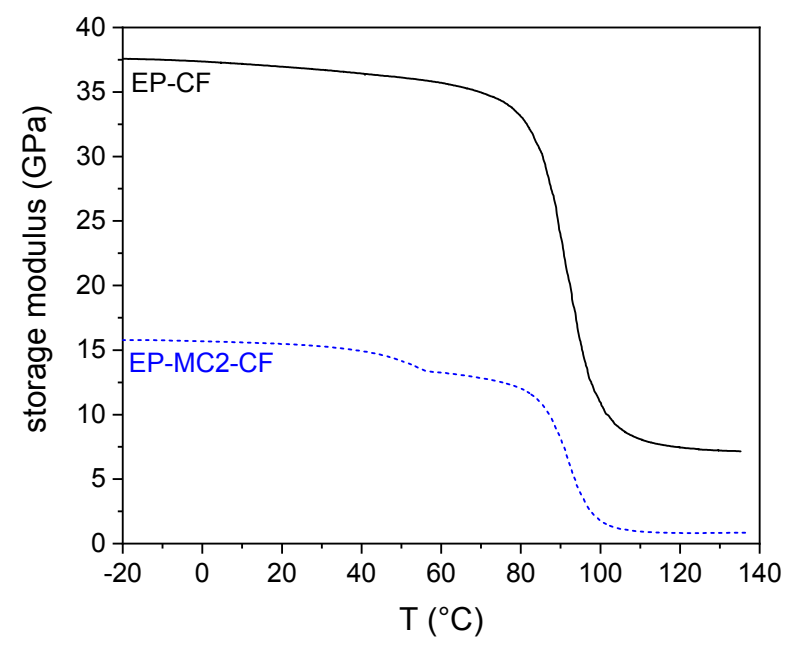

(a)

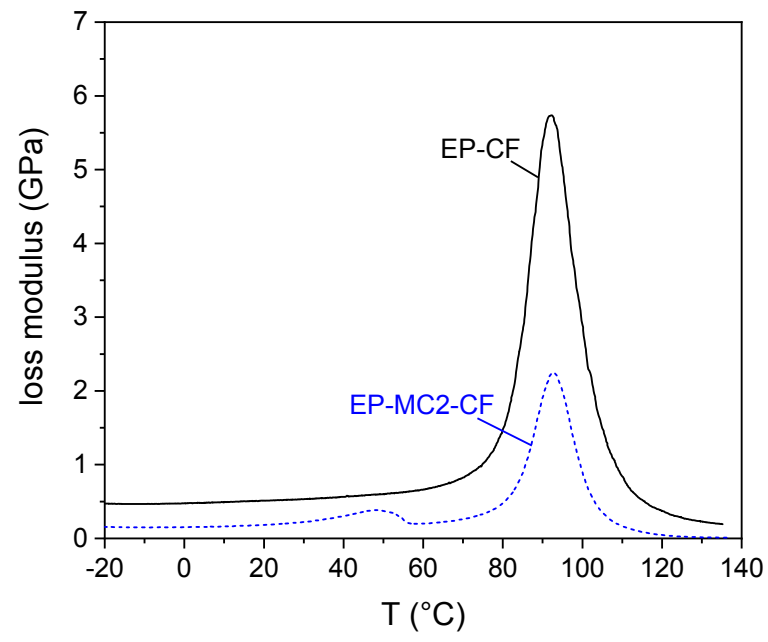

(b)

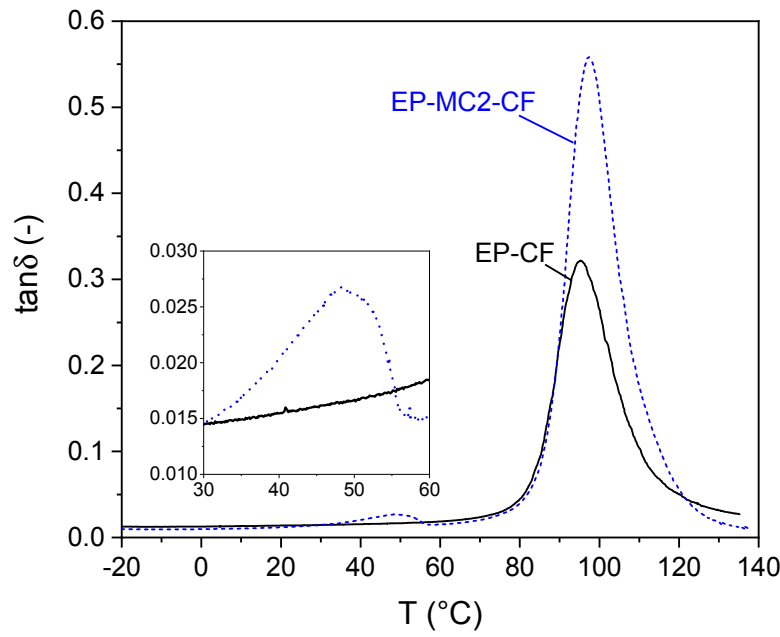

(c)

Figure 12. DMA thermograms of the prepared laminates. (a) Storage modulus $E^{\prime}$, (b) loss modulus E", (c) tan $\delta$. 
Both laminates experience a sharp decrease in the storage modulus in correspondence to the glass transition of the epoxy resin. The position of the glass transition temperature, determined as the peak temperature of the E" or tan $\delta$ signals, is not sensibly affected by the presence of the PCM. The laminate containing the microcapsules presents an additional signal at the melting of docosane, evidenced by a step in the storage modulus and non-symmetrical peaks in the trends of $\mathrm{E}^{\prime \prime}$ and $\tan \delta$. The storage modulus after the melting phenomenon is approx. $84 \%$ of the value at $0{ }^{\circ} \mathrm{C}$, while the sample EP-CF experiences a much smaller decrease over the same temperature interval. These trends in the DMA signals due to a PCM were also observed in previous research of our group [37], and a deeper investigation of these phenomena would be interesting to investigate a melting/crystallization phase change through DMA.

\subsubsection{Thermal Camera Imaging}

A simple test with a thermal camera was performed on the laminates to check their heat storage/management capability. Figure 13 shows the trend of the surface temperature of each laminate upon natural cooling at room conditions. In the sample EP-MC2-CF the temperature decreases with a plateau-like trend induced by the heat released at the crystallization of docosane, which delays the cooling considerably with respect to the sample EP-CF. This test helps in highlighting the potential of PCM-enhanced laminates in thermal management applications.

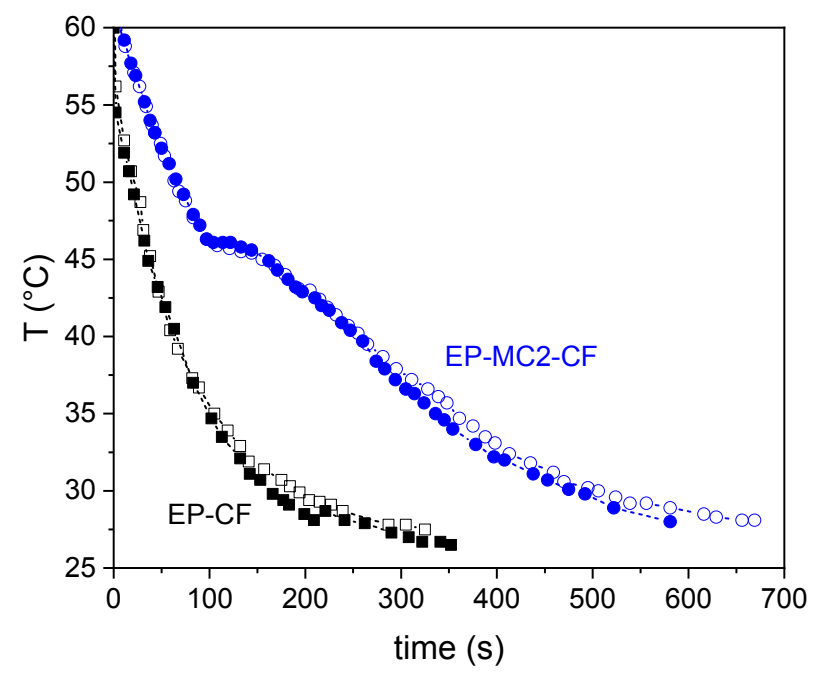

Figure 13. Results of the thermal camera test on the prepared laminates. For reach laminate, the test was repeated on both sides.

\section{Conclusions}

In this work, docosane was encapsulated via a sol-gel process in organosilica shells of two different sizes, and the top-performing microcapsules were embedded in an epoxy/carbon laminate to manufacture multifunctional composites combining structural and TES functions. The microcapsules (MC1 and MC2) were extensively characterized and compared to bulk docosane (D) and neat organosilica microspheres (Si). The FTIR spectra of MC1 and MC2 showed all the signals of D and $\mathrm{Si}$, and the analysis suggested that the docosane fraction was considerably higher in MC2 than in MC1, as confirmed by other techniques. The XRD spectrum of MC1 resembled that of the neat organosilica, due to the low docosane fraction, while the spectrum of MC2 contained the patterns of both organosilica and docosane phases, with a probable indication of the presence of the solid rotator phase RII. Solid-state NMR has proved to be a powerful technique to investigate microencapsulated PCMs, providing an in-depth insight into the different microstructures and phases of the samples. In the ${ }^{13} \mathrm{C} C \mathrm{CP}-\mathrm{MAS}$ spectra, the sample MC2 showed some minor peaks with an upfield shift of approx. $2 \mathrm{ppm}$ next to the $\alpha, \beta$ and $\varepsilon$ signals, appreciable also in the proton-decoupled spectrum, while the 
spectrum of MC1 contains only the upfield shifted signals. This shift is related to the presence of a rotator phase or to the reduced docosane chain mobility and interaction with the shell wall ( $\gamma$-gauche effect). From the areas of $\alpha$ and $\alpha^{\prime}$ signals, it was possible to estimate that the rotator phase is the $20 \%$ of all the encapsulated alkane for sample MC2, while for the MC1 it represents the $100 \%$. DSC analysis revealed that the melting and crystallization temperatures decreased upon encapsulation, which is due to the difficulty to form perfect crystals in a confined volume and the need for a higher supercooling to start the crystallization. The melting enthalpy measured on MC2, the top-performing microcapsules, was $143 \mathrm{~J} / \mathrm{g}$, which implies an encapsulation efficiency of approx. $60 \%$.

In the second part of the work, the microcapsules MC2 were used to produce a structural TES composite. Three-point bending test evidenced a decrease in the mechanical properties of both epoxy and epoxy/carbon laminate after microcapsule addition, associated with the presence of microcapsules agglomerates and the not optimal capsule-epoxy adhesion, both evidenced by scanning electron microscopy (SEM), and dynamic mechanical analysis (DMA) highlighted a decrease of approx. $15 \%$ in the storage modulus after docosane melting. The thermal and heat storage properties were investigated through DSC and TGA, and a thermal camera imaging test was useful to assess the thermal management properties and to visualize the heat released during docosane crystallization.

This work contributed to highlight the potentialities of the sol-gel route as a PCM encapsulation technique, to shed light on the change in structural, microstructural and thermal properties due to confinement effect and interaction with the shell wall, and to study the effect of PCM microcapsules on the properties of a carbon/epoxy laminate, in the perspective to produce multifunctional composites. Further studies will be devoted to improving both the emulsion conditions, to increase the encapsulation efficiency, and the microcapsule dispersion in a polymer matrix, to preserve its mechanical properties. Moreover, the thermal reliability of the produced PCM microcapsules will also be evaluated through cyclic DSC tests.

Supplementary Materials: The following are available online at http:/www.mdpi.com/1996-1944/12/8/1286/s1, Figure S1: ${ }^{13} \mathrm{C}$ proton-decoupled MAS NMR spectra of docosane (D), MC1 and MC2 microcapsules and the neat organosilica microparticles ( $\mathrm{Si}$ ), Figure $\mathrm{S} 2$ : $\mathrm{T}_{\mathrm{C}}$ curves of the carbons detected in the ${ }^{13} \mathrm{C} C \mathrm{CP}-\mathrm{MAS}$ spectra for MC2 (black for original signals, blue spots for interfacial peaks) and MC1 samples (red spots): (a)+ (b)+ (c) chain methylenes from C-3, (d) C-2 methylenes, (e) methyls, (f) MTES methyls, Figure S3: The activation energy for the melting and crystallization processes calculated through the Arrhenius equation (slope of the linear regression). Table S1: $\mathrm{T1}$ C relaxation times of the two samples expressed in seconds, Table S2: Main results of the TGA tests on the bulk (D) and microencapsulated (MC1 and MC2) docosane and the neat organosilica microparticles (Si). Table S3: Main results of the DSC tests on the samples EP-MC2 and EP-MC2-CF. The table reports data of the phase change temperatures and enthalpies, as well as the experimental mass fractions of docosane and MC2, Table S4: Main results of the TGA tests on the matrices EP and EP-MC2, and on the laminates EP-CF and EP-MC2-CF, Table S5: Main results of the DMA tests on the laminates EP-CF and EP-MC2-CF.

Author Contributions: Conceptualization, G.F., S.D. and A.P.; Methodology, G.F., S.D. and F.M.; Validation, G.F., S.D., E.C., and F.M.; Investigation, G.F., S.D., E.C., R.C. and F.M.; Resources, S.D., E.C., R.C. and A.P.; Data Curation, G.F. and F.M.; Writing-Original Draft Preparation, G.F.; Writing-Review \& Editing, G.F., S.D., E.C., R.C. and A.P.; Supervision, S.D. and A.P.; Project Administration, S.D. and A.P.

Funding: This research received no external funding.

Acknowledgments: The company Elantas Europe S.r.l. (Collecchio (PR), Italy) is gratefully acknowledged for providing some of the reagents.

Conflicts of Interest: The authors declare no conflict of interest.

\section{References}

1. Fleischer, A.S. Thermal Energy Storage Using Phase Change Materials_Fundamentals and Applications; Springer Briefs in Applied Science and Technology, Thermal Engineering and Applied Science; Springer: Minneapolis, MN, USA, 2015.

2. Kenisarin, M.M.; Kenisarina, K.M. Form-stable phase change materials for thermal energy storage. Renew. Sustain. Energy Rev. 2012, 16, 1999-2040. [CrossRef] 
3. Xie, N.; Luo, J.; Li, Z.; Huang, Z.; Gao, X.; Fang, Y.; Zhang, Z. Salt hydrate/expanded vermiculite composite as a form-stable phase change material for building energy storage. Sol. Energy Mater. Sol. Cells 2019, 189, 33-42. [CrossRef]

4. Kuznik, F.; David, D.; Johannes, K.; Roux, J.J. A review on phase change materials integrated in building walls. Renew. Sustain. Energy Rev. 2011, 15, 379-391. [CrossRef]

5. Abhat, A. Low temperature latent heat thermal energy storage: Heat storage materials. Sol. Energy 1983, 30, 313-332. [CrossRef]

6. Agyenim, F.; Hewitt, N.; Eames, P.; Smyth, M. A review of materials, heat transfer and phase change problem formulation for latent heat thermal energy storage systems (LHTESS). Renew. Sustain. Energy Rev. 2010, 14, 615-628. [CrossRef]

7. Khadiran, T.; Hussein, M.Z.; Zainal, Z.; Rusli, R. Encapsulation techniques for organic phase change materials as thermal energy storage medium: A review. Sol. Energy Mater. Sol. Cells 2015, 143, 78-98. [CrossRef]

8. Fan, L.; Khodadadi, J.M. Thermal conductivity enhancement of phase change materials for thermal energy storage: A review. Renew. Sustain. Energy Rev. 2011, 15, 24-46. [CrossRef]

9. Pielichowska, K.; Pielichowski, K. Phase change materials for thermal energy storage. Prog. Mater. Sci. 2014, 65, 67-123. [CrossRef]

10. Chen, F.; Wolcott, M. Polyethylene/paraffin binary composites for phase change material energy storage in building: A morphology, thermal properties, and paraffin leakage study. Sol. Energy Mater. Sol. Cells 2015, 137, 79-85. [CrossRef]

11. Chen, F.; Wolcott, M.P. Miscibility studies of paraffin/polyethylene blends as form-stable phase change materials. Eur. Polym. J. 2014, 52, 44-52. [CrossRef]

12. Lin, Y.; Zhu, C.; Fang, G. Synthesis and properties of microencapsulated stearic acid/silica composites with graphene oxide for improving thermal conductivity as novel solar thermal storage materials. Sol. Energy Mater. Sol. Cells 2019, 189, 197-205. [CrossRef]

13. Jamekhorshid, A.; Sadrameli, S.M.; Farid, M. A review of microencapsulation methods of phase change materials (PCMs) as a thermal energy storage (TES) medium. Renew. Sustain. Energy Rev. 2014, 31, 531-542. [CrossRef]

14. Hassan, A.; Shakeel Laghari, M.; Rashid, Y. Micro-encapsulated phase change materials: A review of encapsulation, safety and thermal characteristics. Sustainability 2016, 8, 1046. [CrossRef]

15. Sarı, A.; Alkan, C.; Karaipekli, A. Preparation, characterization and thermal properties of PMMA/n-heptadecane microcapsules as novel solid-liquid microPCM for thermal energy storage. Appl. Energy 2010, 87, 1529-1534. [CrossRef]

16. Brown, E.N.; White, S.R.; Sottos, N.R. Microcapsule induced toughening in a self-healing polymer composite. J. Mater. Sci. 2004, 39, 1703-1710. [CrossRef]

17. Fortuniak, W.; Slomkowski, S.; Chojnowski, J.; Kurjata, J.; Tracz, A.; Mizerska, U. Synthesis of a paraffin phase change material microencapsulated in a siloxane polymer. Colloid Polym. Sci. 2013, 291, 725-733. [CrossRef] [PubMed]

18. Zhao, J.; Yang, Y.; Li, Y.; Zhao, L.; Wang, H.; Song, G.; Tang, G. Microencapsulated phase change materials with $\mathrm{TiO}_{2}$-doped PMMA shell for thermal energy storage and UV-shielding. Sol. Energy Mater. Sol. Cells 2017, 168, 62-68. [CrossRef]

19. Peng, H.; Zhang, D.; Ling, X.; Li, Y.; Wang, Y.; Yu, Q.; She, X.; Li, Y.; Ding, Y. N-alkanes phase change materials and their microencapsulation for thermal energy storage: A critical review. Energy Fuels 2018, 32, 7262-7293. [CrossRef]

20. Yu, S.; Wang, X.; Wu, D. Microencapsulation of n-octadecane phase change material with calcium carbonate shell for enhancement of thermal conductivity and serving durability: Synthesis, microstructure, and performance evaluation. Appl. Energy 2014, 114, 632-643. [CrossRef]

21. Fang, G.; Chen, Z.; Li, H. Synthesis and properties of microencapsulated paraffin composites with $\mathrm{SiO}_{2}$ shell as thermal energy storage materials. Chem. Eng. J. 2010, 163, 154-159. [CrossRef]

22. Cao, L.; Tang, F.; Fang, G. Synthesis and characterization of microencapsulated paraffin with titanium dioxide shell as shape-stabilized thermal energy storage materials in buildings. Energy Build. 2014, 72, 31-37. [CrossRef] 
23. Cao, L.; Tang, F.; Fang, G. Preparation and characteristics of microencapsulated palmitic acid with $\mathrm{TiO}_{2}$ shell as shape-stabilized thermal energy storage materials. Sol. Energy Mater. Sol. Cells 2014, 123, $183-188$. [CrossRef]

24. Zhang, H.; Sun, S.; Wang, X.; Wu, D. Fabrication of microencapsulated phase change materials based on n-octadecane core and silica shell through interfacial polycondensation. Colloids Surf. A Physicochem. Eng. Asp. 2011, 389, 104-117. [CrossRef]

25. Zhang, H.; Wang, X.; Wu, D. Silica encapsulation of n-octadecane via sol-gel process: A novel microencapsulated phase-change material with enhanced thermal conductivity and performance. J. Colloid Interface Sci. 2010, 343, 246-255. [CrossRef] [PubMed]

26. Ciriminna, R.; Sciortino, M.; Alonzo, G.; de Schrijver, A.; Pagliaro, M. From molecules to systems: Sol-gel microencapsulation in silica-based materials. Chem. Rev. 2011, 111, 765-789. [CrossRef] [PubMed]

27. Sun, K.; Liu, H.; Wang, X.; Wu, D. Innovative design of superhydrophobic thermal energy-storage materials by microencapsulation of $\mathrm{n}$-docosane with nanostructured $\mathrm{ZnO} / \mathrm{SiO}_{2}$ shell. Appl. Energy 2019, 237, 549-565. [CrossRef]

28. Chen, Z.; Cao, L.; Shan, F.; Fang, G. Preparation and characteristics of microencapsulated stearic acid as composite thermal energy storage material in buildings. Energy Build. 2013, 62, 469-474. [CrossRef]

29. Wang, L.Y.; Tsai, P.S.; Yang, Y.M. Preparation of silica microspheres encapsulating phase-change material by sol-gel method in o/w emulsion. J. Microencapsul. 2006, 23, 3-14. [CrossRef] [PubMed]

30. Chen, Z.; Cao, L.; Fang, G.; Shan, F. Synthesis and characterization of microencapsulated paraffin microcapsules as shape-stabilized thermal energy storage materials. Nanoscale Microscale Thermophys. Eng. 2013, 17, 112-123. [CrossRef]

31. Tang, F.; Liu, L.; Alva, G.; Jia, Y.; Fang, G. Synthesis and properties of microencapsulated octadecane with silica shell as shape-stabilized thermal energy storage materials. Sol. Energy Mater. Sol. Cells 2017, 160, 1-6. [CrossRef]

32. Alkan, C.; Sarı, A.; Karaipekli, A.; Uzun, O. Preparation, characterization, and thermal properties of microencapsulated phase change material for thermal energy storage. Sol. Energy Mater. Sol. Cells 2009, 93, 143-147. [CrossRef]

33. Felix De Castro, P.; Ahmed, A.; Shchukin, D.G. Confined-volume effect on the thermal properties of encapsulated phase change materials for thermal energy storage. Chemistry 2016, 22, 4389-4394. [CrossRef]

34. Felix De Castro, P.; Shchukin, D.G. New polyurethane/docosane microcapsules as phase-change materials for thermal energy storage. Chemistry 2015, 21, 11174-11179. [CrossRef] [PubMed]

35. Friedrich, K. Routes for Achieving Multifunctionality in Reinforced Polymers and Composite Structures. In Multifunctionality of Polymer Composites: Challenges and New Solutions; Friedrich, K., Breuer, U., Eds.; Elsevier: Waltham, MA, USA, 2015; pp. 3-41.

36. Fredi, G.; Dorigato, A.; Fambri, L.; Pegoretti, A. Wax confinement with carbon nanotubes for phase changing epoxy blends. Polymers 2017, 9, 405. [CrossRef] [PubMed]

37. Fredi, G.; Dorigato, A.; Fambri, L.; Pegoretti, A. Multifunctional epoxy/carbon fiber laminates for thermal energy storage and release. Compos. Sci. Technol. 2018, 158, 101-111. [CrossRef]

38. Fredi, G.; Dorigato, A.; Pegoretti, A. Multifunctional glass fiber/polyamide composites with thermal energy storage/release capability. eXPRESS Polym. Lett. 2018, 12, 349-364. [CrossRef]

39. Dorigato, A.; Fredi, G.; Pegoretti, A. Novel phase change materials using thermoplastic composites. In Proceedings of the 9th International Conference on "Times of Polymers and Composites", Ischia, Italy, 17-21 June 2018; pp. 020044-1-020044-4.

40. Fredi, G.; Dorigato, A.; Pegoretti, A. Novel reactive thermoplastic resin as a matrix for laminates containing phase change microcapsules. Polym. Compos. 2019. [CrossRef]

41. Fredi, G.; Dorigato, A.; Unterberger, S.; Artuso, N.; Pegoretti, A. Discontinuous carbon fiber/polyamide composites with microencapsulated paraffin for thermal energy storage. J. Appl. Polym. Sci. 2019, 136, 47408. [CrossRef]

42. Dorigato, A.; Fredi, G.; Pegoretti, A. Application of the thermal energy storage concept to novel epoxy-short carbon fiber composites. J. Appl. Polym. Sci. 2019, 136, 47434. [CrossRef]

43. Dirè, S.; Tagliazucca, V.; Callone, E.; Quaranta, A. Effect of functional groups on condensation and properties of sol-gel silica nanoparticles prepared by direct synthesis from organoalkoxysilanes. Mater. Chem. Phys. 2011, 126, 909-917. [CrossRef] 
44. Wang, F.; Zhang, C.; Liu, J.; Fang, X.; Zhang, Z. Highly stable graphite nanoparticle-dispersed phase change emulsions with little supercooling and high thermal conductivity for cold energy storage. Appl. Energy 2017, 188, 97-106. [CrossRef]

45. Shao, J.; Darkwa, J.; Kokogiannakis, G. Review of phase change emulsions (PCMEs) and their applications in HVAC systems. Energy Build. 2015, 94, 200-217. [CrossRef]

46. Wang, F.; Lin, W.; Ling, Z.; Fang, X. A comprehensive review on phase change material emulsions: Fabrication, characteristics, and heat transfer performance. Sol. Energy Mater. Sol. Cells 2019, 191, 218-234. [CrossRef]

47. Park, J.-H.; Oh, C.; Shin, S.-I.; Moon, S.-K.; Oh, S.-G. Preparation of hollow silica microspheres in w/o emulsions with polymers. J. Colloid Interface Sci. 2003, 266, 107-114. [CrossRef]

48. Proverbio, Z.E.; Bardavid, S.M.; Arancibi, E.L.; Schulz, P.C. Hydrophile-lipophile balance and solubility parameter of cationic surfactants. Colloids Surf. A Physicochem. Eng. Asp. 2003, 214, 167-171. [CrossRef]

49. Cardoso, K.P.; Ferrão, L.F.A.; Kawachi, E.Y. Preparation of paraffin-based solid combustible for hybrid propulsion rocket motor. J. Propuls. Power 2017, 33, 448-455. [CrossRef]

50. Socrates, G. Infrared and Raman Characteristic Group Frequencies: Tables and Charts; Wiley: Oxford, UK, 2001.

51. Dirè, S.; Borovin, E.; Ribot, F. Architecture of Silsesquioxanes. In Handbook of Sol-Gel Science and Technology: Processing, Characterization and Applications; Klein, L., Aparicio, M., Jitanu, A., Eds.; Springer: New York, NY, USA, 2018.

52. Nouar, H.; Petitjean, D.; Bouroukba, M.; Dirand, M. Binary phase diagram of the system: N-docosane-n-tricosane. J. Mol. Struct. 1998, 443, 197-204. [CrossRef]

53. Lüth, H.; Nyburg, S.C.; Robinson, P.M.; Scott, H.G. Crystallographic and calorimetric phase studies of the n-eicosane, $\mathrm{C}_{20} \mathrm{H}_{42}$ : N-docosane, $\mathrm{C}_{22} \mathrm{H}_{46}$ system. Mol. Cryst. Liq. Cryst. 1974, 27, 337-357. [CrossRef]

54. Wang, D.; Sui, J.; Qi, D.; Wei, Y.; Wang, X.; Lan, X.Z. Phase transition of docosane in nanopores. J. Therm. Anal. Calorim. 2019, 135, 2869-2877. [CrossRef]

55. Speight, R.J.; Rourke, J.P.; Wong, A.; Barrow, N.S.; Ellis, P.R.; Bishop, P.T.; Smith, M.E. ${ }^{1} \mathrm{H}$ and ${ }^{13} \mathrm{C}$ solutionand solid-state NMR investigation into wax products from the Fischer-Tropsch process. Solid State Nucl. Magn. Reason. 2011, 39, 58-64. [CrossRef]

56. Okazaki, M.; Toriyama, K. Alternation of spin-lattice relaxation-times for even and odd linear alkane crystals-A high-resolution solid-state NMR study. J. Phys. Chem. 1989, 93, 2883-2885. [CrossRef]

57. Möller, M.; Cantow, H.-J.; Drotloff, H.; Emeis, D.; Lee, K.-S.; Wegner, G. Phase transitions and defect structures in the lamellar surface of polyethylene and n-alkane crystallites. Magic angle spinning ${ }^{13} \mathrm{C}$ NMR studies. Makromol. Chem. 1987, 187, 1237-1252. [CrossRef]

58. Inoue, D.; Kurosu, H.; Chen, Q.; Ando, I. Structural and dynamical studies of ${ }^{13}$ C-labeled polyethylene adsorbed on the surface of silica gel by high-resolution solid-state ${ }^{13} \mathrm{C}$ NMR spectroscopy. Acta Polym. 1995, 46, 420-423. [CrossRef]

59. Liu, X.; Lou, Y. Preparation of microencapsulated phase change materials by the sol-gel process and its application on textiles. Fibres Text. East. Eur. 2015, 23, 63-67.

60. Li, B.; Liu, T.; Hu, L.; Wang, Y.; Gao, L. Fabrication and properties of microencapsulated paraffin $/ \mathrm{SiO}_{2} \mathrm{phase}$ change composite for thermal energy storage. ACS Sustain. Chem. Eng. 2013, 1, 374-380. [CrossRef]

61. Sun, N.; Xiao, Z. Synthesis and performances of phase change materials microcapsules with a polymer/bn/tio2 hybrid shell for thermal energy storage. Energy Fuels 2017, 31, 10186-10195. [CrossRef]

62. Wang, S.; Tozaki, K.-i.; Hayashi, H.; Hosaka, S.; Inaba, H. Observation of multiple phase transitions in n-c22h46 using a high resolution and super-sensitive DSC. Thermochim. Acta 2003, 408, 31-38. [CrossRef]

63. Anghel, E.M.; Georgiev, A.; Petrescu, S.; Popov, R.; Constantinescu, M. Thermo-physical characterization of some paraffins used as phase change materials for thermal energy storage. J. Therm. Anal. Calorim. 2014, 117, 557-566. [CrossRef]

(C) 2019 by the authors. Licensee MDPI, Basel, Switzerland. This article is an open access article distributed under the terms and conditions of the Creative Commons Attribution (CC BY) license (http://creativecommons.org/licenses/by/4.0/). 